\title{
EL REGISTRO INTERNACIONAL: IMPLEMENTACIÓN EN ESPAÑA DEL CONVENIO DE CIUDAD DEL CABO SOBRE GARANTÍAS INTERNACIONALES Y SU PROTOCOLO AERONÁUTICO
}

\author{
THE INTERNATIONAL REGISTRY: IMPLEMENTATION OF THE \\ CAPE TOWN CONVENTION ON INTERNATIONAL INTERESTS \\ AND ITS AIRCRAFT PROTOCOL IN SPAIN
}

\author{
Ma José Castellanos Ruiz \\ Profesora Visitante de Derecho Internacional Privado \\ Universidad Carlos III de Madrid
}

Recibido: 13/01/2017 / Aceptado: 23/01/2017

DOI: https://doi.org/10.20318/cdt.2017.3613

\begin{abstract}
Resumen: El Convenio de Ciudad del Cabo sobre garantías internacionales y su Protocolo Aeronáutico han entrado en vigor para España el 1 de marzo de 2016. El Registro Internacional es una de las piezas clave del "Sistema de Ciudad del Cabo" junto con las garantías internacionales. En este sentido, España ha realizado las declaraciones pertinentes a dicho instrumento internacional, así como ha elaborado nuevas normas, para que el funcionamiento del Registro Internacional sea una realidad.

Palabras clave: Convenio de Ciudad del Cabo, Protocolo Aeronáutico, Registro Internacional, garantías internacionales, aeronaves, células de aeronaves, motores de aeronaves, helicópteros.

Abstract: The Cape Town Convention on international interests and its Aircraft Protocol have entered into force in Spain on 1 March 2016. The International Registry is one of the key pieces of the "Cape Town System" together with the international interests. In this sense, Spain has made the relevant declarations to this international instrument, as well as it has developed new rules, so that the operation of the International Registry becomes a reality.

Keywords: Cape Town Convention, Aircraft Protocol, International Registry, international interests, aircrafts, airframes, aircraft engines, helicopters.
\end{abstract}

Sumario: I. El "Sistema de Ciudad del Cabo". II. El Registro Internacional: 1. Características. 2. Tipos de garantías inscribibles. III. La "implementación” en España del Registro Internacional: 1. El Registro de Bienes Muebles como punto de acceso autorizante. 2 El Registro de Matrícula de Aeronaves Civiles. IV. La práctica registral en la materia: 1. Inscripción de las garantías en el Registro de Bienes Muebles. 2. Inscripción de una IDERA (Irrevocable Deregistration and Express Request Authorization). V. Cuestiones pendientes. 


\section{El "Sistema de Ciudad del Cabo"}

1. El Registro Internacional de garantías sobre elementos de equipo aeronáutico se enmarca dentro del denominado de forma breve como "Sistema de Ciudad del Cabo". Tanto el Convenio de Ciudad del Cabo 2001 relativo a garantías internacionales sobre elementos de equipo móvil, como su Protocolo Aeronáutico son de aplicación por los Estados que lo hayan ratificado, aprobado, aceptado o adherido, después de la entrada en vigor de ambos instrumentos. Así pues, el Convenio de Ciudad del Cabo y su Protocolo Aeronáutico entraron en vigor a la vez, el 1 de marzo del 2006 ${ }^{2}$. A la fecha de entrada en vigor tanto del Convenio como del Protocolo, había 9 ratificaciones, pero en la actualidad, mientras que el Convenio cuenta con 73 Estados contratantes, el Protocolo Aeronáutico cuenta con 65 Estados contratantes. Esto se debe a que hay Estados que forman parte del Convenio, pero no del Protocolo ${ }^{3}$.

Además de los Estados contratantes, la Unión Europea también forma parte del "Sistema de Ciudad del Cabo", pero como "Organización regional de integración económica", de acuerdo con el art. 48 del Convenio y el art. 27 del Protocolo Aeronáutico. Aunque para la Unión Europea ambos instrumentos entraron en vigor el 1 de agosto de 2009, su adhesión no implica que los Estados miembros tengan que ratificar el Convenio y su Protocolo. En este sentido, debido a que determinados aspectos que regula el "Sistema de Ciudad del Cabo" afecta a competencias repartidas entre la Unión Europea y los Estados, se puede afirmar que sin la adhesión realizada por la Unión Europea, los Estados no podrían ratificar por completo y con plenos efectos el Convenio y su Protocolo Aeronáutico ${ }^{4}$.

Ahora bien, como el Convenio y su Protocolo vinculan a los Estados miembros en el sentido de que contienen disposiciones referidas a aspectos en los que la Unión Europea tiene competencias, los Estados miembros deben tomar las medidas oportunas para cumplir e implementar tales disposiciones, a través de las declaraciones o reservas que pueden realizar los Estados en el momento de su adhesión. Sin embargo, es necesaria la ratificación de cada Estado para que el Convenio y el Protocolo desplieguen todos sus efectos. De hecho, en el momento de la adhesión de la Unión Europea, Irlanda y Luxemburgo ya eran parte de ambos instrumentos. Desde entonces los Estados miembros que han ratificado el "Sistema de Ciudad del Cabo" son Malta, Letonia, Gran Bretaña, Dinamarca, España y Suecia. Por otro lado, la decisión de adhesión de la Unión Europea a ambos instrumentos no es aplicable a Dinamarca. Además, mencionar que aunque los Países Bajos están dentro del cómputo de Estados que han ratificado el Convenio y el Protocolo, éstos sólo son aplicables a las Antillas Holandesas y a Aruba, tal y como figura en la declaración prevista en el art. 52.1 del Convenio para aquellos Estados que están formados por varias unidades territoriales, como es el caso de los Países Bajos ${ }^{5}$. España por su parte, primero ratificó el Convenio, el cual entró en vigor el 1 de octubre del 2013, mientras que el Protocolo Aeronáutico es de aplicación desde el 1 de marzo de 2016, a excepción de varios artículos que entraron en vigor el 1 de junio de ese mismo año ${ }^{6}$.

1 I. Heredia Cervantes, “Análisis de la adhesión de España al Protocolo Aeronáutico del Convenio de Ciudad del Cabo", La Ley mercantil, núm. 21, 1 enero 2016, p. 2.

2 La fecha de entrada en vigor coincide con el primer día del mes siguiente a la finalización de un período de tres meses posterior a la fecha del depósito del octavo instrumento de ratificación, aprobación, aceptación o adhesión con respecto al Protocolo (art. 49.1 Convenio y XXVIII.1 Protocolo). Para el resto de Estados que se han adherido posteriormente a ambos instrumentos, la fecha de entrada en vigor se produce el primer día del mes siguiente a la finalización de un período de tres meses posterior a la fecha de depósito de sus instrumentos de ratificación, aprobación, aceptación o adhesión a dicho Protocolo, tal y como establece el art. 49.2 del Convenio y el art. XXVIII.2 del Protocolo Aeronáutico.

3 Aunque para su entrada en vigor era necesario la ratificación de ocho Estados, Senegal como noveno Estado contratante también lo había ratificado aunque su fecha de entrada en vigor fuese dos meses más tarde. En cuanto al estado de las ratificaciones del Convenio vid. http://www.unidroit.org/fr/etat-2001 capetown (consultado el 16 de noviembre del 2016). Mientras que respecto del estado de las ratificaciones del Protocolo Aeronáutico vid. http://www.unidroit.org/fr/etat-2001 capetownaircraft (consultado el 16 de noviembre del 2016).

4 T. Rodríguez de las Heras Ballell, Las garantías mobiliarias sobre equipo aeronáutico en el comercio internacional. El Convenio de Ciudad del Cabo y su protocolo, Marcial Pons, Madrid, 2012, p. 26.

${ }^{5}$ La declaración que ha hecho los Países Bajos es la siguiente: "Pursuant to Article 52, paragraph 1, of the Convention, the Kingdom of the Netherlands declares that the Convention is to apply to the following territorial units: the Netherlands Antilles and Aruba". Aruba es uno de los Estados bajo cuya bandera de conveniencia se matriculan muchas aeronaves, de ahí que esta unidad territorial de los Países Bajos se haya adherido al "Sistema de Ciudad del Cabo".

${ }^{6}$ Instrumento de Adhesión de España al Convenio relativo a garantías internacionales sobre elementos de equipo móvil, 
Por lo tanto, el Convenio y su Protocolo Aeronáutico son textos internacionales de naturaleza mixta que se proyectan sobre competencias de los Estados y de la Unión Europea. Como consecuencia de su especial naturaleza, la Unión Europea ha firmado el Convenio y el Protocolo Aeronáutico, pero haciendo reservas en materias que son de su competencia, como ocurre en el caso de las normas sobre competencia judicial internacional, al estar recogidas, en ese momento, en el Reglamento 44/2001, en la actualidad reemplazado por el Reglamento 1215/2012, relativo a la competencia judicial, el reconocimiento y la ejecución de resoluciones en materia civil y mercantil; y con respecto a las normas sobre la determinación de la ley aplicable a las obligaciones contractuales y a los procedimientos de insolvencia, al estar contenidas respectivamente en el Reglamento 593/2008 (Reglamento Roma I) sobre obligaciones contractuales y en el Reglamento 1346/2000 sobre procedimientos de insolvencia, éste último reemplazado en el Reglamento 2015/8487.

La ratificación de ambos instrumentos el 1 de marzo de 2006 por parte de Estados Unidos tiene una importancia significativa por el puesto que ocupa en la industria aeronáutica, de manera que ha favorecido la difusión y aceptación de ambos instrumentos a nivel mundial. Otros países que se deben destacar como Estados contratantes son Canadá o Brasil, por tratarse de los dos Estados donde se encuentran los otros dos fabricantes de aeronaves, Bombardier y Embraer respectivamente, aunque los mayores fabricantes son Airbus y Boeing. También se debe mencionar a la Federación Rusa, a Emiratos Árabes Unidos, a Arabia Saudí o a China, por ser Estados también de gran importancia en el sector aeronáutico, en cuanto al volumen de adquisición de aeronaves.

2. El Convenio de Ciudad del Cabo de 2001 relativo a garantías internacionales sobre elementos de equipo móvil adoptado en la Conferencia diplómática celebrada en dicha ciudad sudafricana, entre los días 29 de octubre y 16 de noviembre de 2001, es el resultado de la colaboración del International Institute for the Unification of Private Law (UNIDROIT) y de la Organización de Aviación Civil Internacional $(O A C I)$, con el objetivo de dar soluciones concretas a los problemas que se plantean en determinados sectores caracterizados por su elevada complejidad, entre los que está el sector aeronáutico ${ }^{8}$. Además, ha contado con el patrocinio del International Air Transport Association (IATA) y del Aviation Working Group $(A W G)$, pero sobre todo éste último a través de su página web, en la que se recogen documentos de especial interés sobre la implementación del Convenio y el Prococolo en los Estados, ha contribuido a la ratificación por parte de los Estados del "Cape Town Treaty", que es como el $A W G$ denomina al Convenio de Ciudad del Cabo y su Protocolo Aeronáutico?.

hecho en Ciudad del Cabo el 16 de noviembre de 2001, BOE núm. 238, 4 octubre 2013; Instrumento de adhesión al Protocolo sobre cuestiones específicas de los elementos de equipo aeronáutico, del Convenio relativo a garantías internacionales sobre elementos de equipo móvil, hecho en Ciudad del Cabo el 16 de noviembre de 2001, BOE núm. 27,1 febrero 2016. Los artículos del Protocolo Aeronáutico que entraron en vigor en España con posterioridad son el 39.1, 39.3, 40 y 53, relativos a determinadas declaraciones a realizar por los Estados referentes a ciertos derechos o garantías, y sobre las autoridades competentes de los Estados para adoptar las medidas contempladas en el Convenio y su Protocolo Aeronáutico.

${ }^{7}$ Las declaraciones de la Unión Europea están contenidas en los Anexos I y II de la Decisión del Consejo núm. 2009/370/ CE, de 6 de abril de 2009, relativa a la adhesión de la Comunidad Europea al Convenio relativo a garantías internacionales sobre elementos de equipo móvil y su Protocolo sobre cuestiones específicas de elementos de equipo aeronáutico, adoptados conjuntamente en Ciudad del Cabo el 16 de noviembre del 2001 (DO núm. L 121, 15 mayo 2009).

${ }^{8}$ R. Goode, Official Commentary. Revised Edition. Convention on International Interests in Mobile Equipment and Protocol Thereto on Matters Specific to Aircraft Equipment, Unidroit, Roma, 2008, pp. 5-7; T. Rodríguez de LAS Heras BaLlell, Las garantías mobiliarias sobre equipo aeronáutico en el comercio internacional. El Convenio de Ciudad del Cabo y su protocolo, Marcial Pons, Madrid, 2012, p. 25.

9 El $A W G$ comenzó a trabajar en 1994 a petición del Instituto Internacional para la Unificación del Derecho Privado (International Institute for the Unification of Private Law, UNIDROIT), como un grupo industrial para contribuir al desarrollo del Convenio de Ciudad del Cabo relativo a garantías internacionales sobre elementos de equipo móvil y el Protocolo sobre cuestiones específicas de los elementos de equipo aeronaútico, el cual fue firmado en 2001. En 2002 el $A W G$ se convirtió en una entidad sin ánimo de lucro y su ámbito de aplicación se ha extendido significativamente. Éste se ha dirigido hacia un amplio rango de materias que afectan a la financiación de la aviación internacional, como puede ser el tema de los seguros. También el $A W G$ sirve de foro en el que se tratan nuevos temas que sus miembros plantean y desarrollan, entre los que están aspectos muy importantes del leasing y de la financiación de la aviación internacional. El $A W G$ está copresidido por Airbus y Boeing, y sus miembros y afiliados comprenden los más importantes fabricantes de la industria aeronáutica y de las instituciones financieras, incluyendo las mayores compañías de leasing del mundo. En definitiva, los miembros de $A W G$ y sus afiliados fabrican principalmente todos los motores y aeronaves comerciales modernas, y alquilan y financian una gran parte de estos equipos 
En este sentido, la especial estructura dual Convenio/Protocolos, impide que el Convenio de Ciudad del Cabo pueda operar independientemente de sus Protocolos, de manera que no sólo existe el Protocolo sobre equipo aeronáutico, sino que existen otros dos Protocolos previstos inicialmente: el segundo es el Protocolo sobre material rodante ferroviario, y el tercero es el Protocolo sobre bienes de equipo espacial, aunque ninguno de los dos ha entrado en vigor a la fecha de presentación de este trabajo ${ }^{10}$. Mientras que el Protocolo sobre material rodante ferroviario necesita la ratificación de sólo dos Estados más, el hecho de que el Protocolo sobre bienes de equipo espacial requiera la ratificación de diez Estados para su entrada en vigor, se debe a que a diferencia de los dos primeros Protocolos que cuentan con el apoyo pleno de los sectores económicos afectados, la extensión del Convenio de Ciudad del Cabo al ámbito de las garantías sobre bienes espaciales no ha tenido tan buena aceptación por un sector de la industria, pues las soluciones ofrecidas por los ordenamientos nacionales han venido dando respuesta a los problemas del sector, por no mencionar que el gran tamaño y la sobrada solvencia de las entidades que operan en dicha industria, ha hecho que se hayan ganado la confianza de los inversores ${ }^{11}$.

Las posibilidades que ofrece el Convenio para las garantías mobiliarias sobre determinados elementos de equipo móvil y la flexibilidad del modelo dual Convenio/ Protocolos ha provocado que se haya pensado en un futuro en extender su aplicación a categorías de bienes, que aunque no están expresamente incluidas en el Convenio, pueden responder a similiares características estructuales y requieren también un tratamiento uniforme para favorecer su financiación y adquisición ${ }^{12}$. El Convenio prevé expresamente su aplicación a los siguientes bienes: "a) células de aeronaves, motores de aeronaves y helicópteros, b) material rodante ferroviario, y c) bienes de equipo espacial"'s. Sin embargo, se ha pensado en la elaboración de un cuarto Protocolo sobre bienes de equipo de uso agrícola, minero y de construcción, como consecuencia de la necesidad de financiación en sectores estratégicos para economías de países en vías de desarrollo; aunque esta posibilidad cuenta con dificultades de tipo técnico, pues las reglas del Convenio están pensadas para bienes naturalmente móviles, perfectamente identificables y de alto valor, requisitos que no cumplen los bienes de equipo utilizados en la agricultura, minería y construcción ${ }^{14}$. Por lo tanto, sólo existen tres Protocolos del Convenio de Ciudad del Cabo, de los que únicamente ha entrado en vigor el Protocolo sobre bienes de equipo aeronáutico.

nuevos. La importancia del $A W G$ es tal que son miembros del mismo las compañías de leasing más importantes que existen en la atualidad y que son GECAS (GE Capital Aviation Service) e ILFC (International Lease Finance Corporation). Vid. La página del $A W G$ está disponible en línea en http://www.awg.aero (consultada el 16 de noviembre del 2016).

${ }^{10}$ El Protocolo sobre material rodante ferroviario se adoptó en la Conferencia Diplomática celebrada en Luxemburgo, el 23 de febrero de 2007, pero sólo cuenta con siete Estados firmantes: Gabón, Italia, Luxemburgo, Suiza, Alemania, Mozambique y Reino Unido; y la Unión Europea, pero esta última en su condición de "Organización regional de integración económica", de acuerdo con el art. XXII del Protocolo; de los que sólo lo han ratificado a noviembre del 2016 Alemania y la Unión Europea, por lo que no está en vigor, pues necesita que cuatro Estados lo hayan ratificado, tal y como se especifica en su art. XXIII (Protocolo ferroviario disponible en línea en http:/www.unidroit.org/fr/instruments/garanties-internationales/protocole-ferroviaire (consultado el 16 de noviembre del 2016)). El Protocolo sobre bienes de equipo espacial, se adoptó y abrió a la firma el 9 de marzo 2012, tras la Conferencia Diplomática celebrada en Berlín del 27 de febrero hasta su adopción el 9 de marzo de 2012, pero sólo lo han firmado cuatro Estados: Alemania, Arabia Saudí, Burkina Faso y Zimbabue, de los que ninguno de ellos lo ha ratificado; por lo que tampoco está en vigor, ya que necesita ser ratificado por diez Estados, en virtud de su art. XXXVIII (Protocolo espacial disponible en línea en http://www.unidroit.org/fr/instruments/garanties-internationales/protocole-spatial (consultado el 16 de noviembre del 2016)).

11 F.-J. Gómez Gálligo/ I. Heredia Cervantes, "El convenio de Ciudad del Cabo y su protocolo sobre bienes de equipo espacial”, Revista Crítica de Derecho Inmobiliario, núm. 731, mayo 2012, p. 1418.

12 T. Rodríguez de las Heras Ballell, Las garantías mobiliarias sobre equipo aeronáutico en el comercio internacional. El Convenio de Ciudad del Cabo y su protocolo, Marcial Pons, Madrid, 2012, p. 27.

13 Art. 2.3 Convenio relativo a garantías internacionales sobre elementos de equipo móvil. Decisión del Consejo núm. 2009/370/CE, de 6 de abril de 2009, relativa a la adhesión de la Comunidad Europea al Convenio relativo a garantías internacionales sobre elementos de equipo móvil y su Protocolo sobre cuestiones específicas de elementos de equipo aeronáutico, adoptados conjuntamente en Ciudad del Cabo el 16 de noviembre del 2001, DO núm. L 121, 15 mayo 2009; art. 2.3 Instrumento de Adhesión de España al Convenio relativo a garantías internacionales sobre elementos de equipo móvil, hecho en Ciudad del Cabo el 16 de noviembre de 2001, BOE núm. 238, 4 octubre 2013.

14 También se planteó desde el comienzo de la preparación del proyecto, la posibilidad de que el Convenio se aplicara a los buques o a las plataformas petrolíferas, pero por motivos diversos se ha excluido su tratamiento por el momento (T. RoDRíGUEz DE las Heras Ballell, Las garantías mobiliarias sobre equipo aeronáutico en el comercio internacional. El Convenio de Ciudad del Cabo y su protocolo, Marcial Pons, Madrid, 2012, p. 27). 
3. Las razones que han motivado la elaboración del Convenio y el Protocolo Aeronáutico con el objetivo de desarrollar una disciplina uniforme que regule determinados aspectos de las garantías mobiliarias, son de dos tipos, de índole económica y de índole jurídica. Por un lado, las de tipo económico se basan en que las garantías favorecen las operaciones de financiación en el mercado y que en el sector aeronáutico son imprescindibles para su funcionamiento, pues son bienes con un coste muy elevado. Por otro lado, las de tipo jurídico se basan en las grandes diferencias existentes entre los ordenamientos en relación con un concepto genérico de lo que en español se ha traducido como "garantías", pero que en inglés se denomina "interests", y que engloba mucho más que el contenido de la garantía como se conoce en Derecho español, ya que incluye los leasing de aeronaves con opción a compra o las compraventas de dichos bienes con reserva de dominio -o incluso las compraventas simples-, que en el caso del Derecho español se trata de figuras que están más próximas al Derecho de propiedad.

El Convenio de Ciudad del Cabo y su Protocolo son dos instrumentos que fueron adoptados para facilitar el leasing y la financiación basada en activos como son los bienes de equipo aeronáuticos, al establecer un régimen jurídico internacional para la constitución, la inscripción y la ejecución de las "garantías internacionales" que se apoya en este tipo de bienes ${ }^{15}$. Para la elaboración de los mismos se han tenido muy en cuenta las exigencias económicas sectoriales, ya que los expertos en el sector llevaron a cabo previamente un análisis económico, que se basó en la experiencia de Estados Unidos en el campo de la financiación privada de las aeronaves civiles en un sector donde existe cada vez más competencia, pero a la vez está condicionado por las coyunturas internacionales.

La financiación sobre activos o "asset-based financing", tan utilizado en el sector aeronáutico en los últimos años, es un método de financiación que se basa en el papel de la garantía sobre el bien financiado. En este esquema de financiación, la devolución y la remuneración de la cantidad adelantada por los prestamistas para la adquisición o la puesta a disposición del bien están aseguradas por los ingresos de la explotación. Por lo tanto, en caso de incumplimiento del deudor, los prestamistas deben poder tomar rápidamente el control de la aeronave y asegurarse así que el bien sigue siendo explotado por otra compañía, porque es al fin y al cabo lo que garantiza la rentabilidad de su inversión. Y es bajo estas condiciones cómo la financiación de los bienes accede a los mercados de capitales, de manera que las deudas o créditos que cuentan con garantías sólidas se transforman en títulos financieros mediante la titulización de las operaciones. En consecuencia, el riesgo soportado por los prestamistas y el coste de su contribución, es decir los intereses que cobran por dicha financiación, está en relación directa con el control real que los prestamistas pueden ejercer sobre el bien financiado en caso de incumplimiento del deudor. Por lo tanto, la transferencia de la propiedad en garantía sería la forma más segura de que los prestamistas puedan ejercer, en caso de que fuese necesario, el control de la aeronave ${ }^{16}$.

En este sentido, las necesidades de la industria aeronáutica se han dado a conocer por medio del $A W G$, que basándose en el análisis del impacto económico inspirado en la experiencia norteamericana y en una legislación favorable a los inversores aeronáuticos, ha destinado todos sus esfuerzos a la negociación del Convenio y el Protocolo Aeronáutico para defender los siguientes aspectos: 1) que en primer lugar, recibiese un trato privilegiado la libertad contractual para prever las consecuencias del eventual incumplimiento del deudor; 2) que se establecieran a continuación unas reglas claras de prioridad en el cobro (transparent priority principle), 3) unas normas para que la ejecución sea rápida (prompt enforcement principle), 4) y unas normas de ejecución específicas para los casos de insolvencia (bankruptcy law enforcement principle $)^{17}$. La aplicación de estos principios en Estados Unidos, sobre todo desde el punto

15 B. Poulain, "L'impact economique du Droit Privé International sur le financement des aeronefs civils. La Convention UNIDROIT du 16 novembre 2001", Revue Française de Droit Aérien et Spatial, Vol. 238, núm. 2, abril - junio, 2006, p. 105.

16 B. Poulain, "L'impact economique du Droit Privé International sur le financement des aeronefs civils. La Convention UNIDROIT du 16 novembre 2001", Revue Française de Droit Aérien et Spatial, Vol. 238, núm. 2, abril - junio, 2006, pp. 111-2.

17 Aunque ya se ha hablado del $A W G$, se debe aclarar que este grupo está formado concretamente por: Airbus y Boeing, como constructores de aeronaves; GE Aircraft, Snecma, Rolls Royce y Pratt \& Whitney, como fabricantes de motores; GECAS e ILFC, como compañías de leasing; y Banque Indosuez, The Long-Term Credit Bank of Japan, Kredistanstalt Für Wiederaufbau, como instituciones financieras implicadas en la financiación aeronáutica (B. PoulaIn, "L'impact economique du Droit Privé International sur le financement des aeronefs civils. La Convention UNIDROIT du 16 novembre 2001", Revue Française de Droit Aérien et Spatial, Vol. 238, núm. 2, abril - junio, 2006, p. 112). Vid. El informe del impacto económico en el que se apoya el $A W G$, realizado por A. Saunders/ I. Walter, Denominado Proposed Unidroit Convention on International Interests 
de vista de los acreedores aeronáuticos en caso de insolvencia, ha tenido un impacto muy beneficioso sobre el sector ${ }^{18}$.

Aunque en el informe en el que se basa el $A W G$ para apoyar los principios mencionados no se tienen en cuenta, se deben mencionar además, los beneficios que podrían obtener las economías de los Estados por parte de las Agencias de Crédito a la Exportación, como consecuencia del refuerzo de la posición de los prestamistas en las transacciones internacionales. En este sentido, con motivo de la ratificación del Convenio y el Protocolo Aeronáutico por parte de Estados Unidos, el Export-Import Bank (Eximbank) de Estados Unidos propuso reducir su comisión en torno a un tercio, sobre la financiación de las grandes aeronaves civiles fabricadas en Estados Unidos para aquellos compradores situados en países que hubiesen ratificado el Convenio y el Protocolo Aeronáutico ${ }^{19}$.

En consecuencia, lo que buscan los bancos o las compañías financieras es que se faciliten las operaciones de financiación de las aeronaves, mediante la reducción del coste de los préstamos y los seguros asociados, y se abra el acceso a los mercados de capitales. Además, como se deduce del informe del impacto económico en el que se apoya el $A W G$ para promover el Convenio y su Protocolo Aeronáutico, se deben tener en cuenta las ganancias macroeconómicas o indirectas derivadas de las deudas exteriores contraídas por los Estados, en materia de inversiones industriales devueltas al sector aeronáutico, o incluso en materia de creación de empleos ${ }^{20}$.

4. Junto con los aspectos económicos que han dado origen a estos instrumentos, coexisten los fundamentos jurídicos, que han provocado que sea UNIDROIT uno de los organismos propulsores de esta iniciativa, siendo en definitiva el depositario legal de ambos instrumentos internacionales ${ }^{21}$. La necesidad de una armonización internacional en materia de "garantías" mobiliarias, entendidas en sentido amplio, ha sido el otro pilar en el que se ha sustentado el Convenio y su Protocolo Aeronáutico, pues existen grandes diferencias entre los ordenamientos estatales, tanto en lo que respecta a los tipos de "garantías" contemplados, como en el reconocimiento de dichas "garantías" en otros Estados ${ }^{22}$.

Con el desarrollo de la economía industrial y de servicios, el tener que cubrir las necesidades del tráfico en general, pero especialmente las del tráfico aéreo, ha llevado a que surgan nuevas necesidades de financiación, lo cual ha provocado un cambio en los mecanismos jurídicos de garantía ${ }^{23}$. La necesidad de tener que utilizar los activos de la empresa, siendo el caso de las aeronaves, como garantía para obtener financiación externa ha provocado que las formas tradicionales de garantías ya no se utilicen. Así por ejemplo, el requisito de la desposesión o desplazamiento del bien, que ha acompañado a las fórmulas clásicas de garantía, impide que el deudor siga utilizando el bien en su actividad productiva para

in Mobile equipment as applicable to aircraft equipmet through the aircraft equipment protocol: economic impact assessment, que está disponible en línea en http://www.awg.aero/assets/docs/EIA.pdf (consultada el 16 de noviembre de 2016).

18 B. Poulain, "L'impact economique du Droit Privé International sur le financement des aeronefs civils. La Convention UNIDROIT du 16 novembre 2001", Revue Française de Droit Aérien et Spatial, Vol. 238, núm. 2, abril - junio, 2006, p. 112.

19 Eximbank Press Release, 29 de octubre de 2004.

20 B. Poulain, "L'impact economique du Droit Privé International sur le financement des aeronefs civils. La Convention UNIDROIT du 16 novembre 2001", Revue Française de Droit Aérien et Spatial, Vol. 238, núm. 2, abril - junio, 2006 , p. 115.

${ }^{21}$ En la página oficial de UNIDROIT se puede acceder a dichos instrumentos, que están disponibles en línea en http://www. unidroit.org (consultados el 16 de septiembre de 2016). Asimismo, la cronología del desarrollo de Convenio y los documentos clave elaborados en relación con el Convenio, así como con respecto al Protocolo Aeronáutico, se detallan en los Anexos XII y XIII respectivamente, del Official Commentary (R. Goode, Official Commentary. Revised Edition. Convention on International Interests in Mobile Equipment and Protocol Thereto on Matters Specific to Aircraft Equipment, Unidroit, Roma, 2008).

${ }^{22}$ Como bien señalan algunos autores, en contraposición con lo que sucede con el Derecho de las obligaciones, y más concretamente con el Derecho de los contratos, los aspectos reales de las transacciones comerciales internacionales no han sido abordados en el proceso de armonización del Derecho Comercial Internacional. Los motivos han sido muy diversos, pero se debe destacar la excesiva preocupación por no interferir en las regulaciones nacionales relativas a la insolvencia, las grandes diferencias existentes entre las familias jurídicas o las exageradas limitaciones al ejercicio de la autonomía de la voluntad, pactos entre la partes que, sin embargo, sí se han favorecido en el ámbito de los contratos (F.-J. Gómez Gálligo/ I. Heredia Cervantes, "El convenio de Ciudad del Cabo y su protocolo sobre bienes de equipo espacial", Revista Crítica de Derecho Inmobiliario, núm. 731, mayo 2012, p. 1419).

23 T. Rodríguez de las Heras Ballell, Las garantías mobiliarias sobre equipo aeronáutico en el comercio internacional. El Convenio de Ciudad del Cabo y su protocolo, Marcial Pons, Madrid, 2012, p. 31. 
satisfacer el crédito, y supone para el acreedor unos costes derivados de la custodia y conservación del bien, cuando éste pretende la satisfacción del crédito por parte del deudor ${ }^{24}$.

Aunque existe cierto rechazo en algunos sistemas jurídicos, se puede comprobar que a nivel de las legislaciones nacionales existe en materia de derechos de garantías un modelo de regulación que se articula en torno a los siguientes objetivos: a) permitir la constitución de una garantía sin imponer la desposesión del bien al deudor y por lo tanto, le permite poder usarlo; b) permitir a las partes adaptar la garantía a las necesidades particulares de sus transacciones, dejando un lugar a la autonomía de la voluntad de las partes, que pueden pactar las modalidades de ejecución de la garantía; c) establecer un sistema eficaz de publicidad de los derechos de garantía constituidos; d) establecer unas reglas claras de prioridad; e) en caso de incumplimiento del deudor, permitir al acreedor garantizado la realización rápida y al valor de mercado, del bien gravado ${ }^{25}$. Estos principios permiten un fortalecimiento de la posición del deudor y en consecuencia que fluya el crédito, como ya se ha mencionado al tratar los aspectos económicos.

Sin embargo, como se trata de bienes muebles, pues los bienes sobre los que se realizan la garantías son helicópteros, células de aeronaves y motores, que cruzan frecuentemente los territorios de diversos Estados, se plantea el problema de cómo el acreedor garantizado puede hacer valer sus derechos. El principio de Derecho internacional privado que establece la ley aplicable a los derechos reales y demás garantías sobre los bienes muebles en general, es el de la ley del lugar de situación del bien, lex rei sitae, y que tiene el efecto de perturbar la continuidad de los derechos de garantía constituidos sobre los bienes ${ }^{26}$. Esto puede llevar a un problema de reconocimiento en un Estado de los derechos constituidos conforme a la ley de otro Estado. Las diferencias existentes entre los ordenamientos en esta materia son todavía grandes y puede suceder en el peor de los casos, que se nieguen a reconocer la eficacia de figuras no conocidas el ordenamiento donde se pretenden hacer valer ${ }^{27}$. Si bien, lo que suele suceder en la práctica es que el titular de los derechos constituidos conforme a la ley de un Estado, no cumplirá probablemente las formalidades necesarias para que dichos derechos sean oponibles frente a terceros en otro Estado, y más concretamente los requisitos locales de publicidad ${ }^{28}$.

En el caso de las aeronaves y de los buques, el principio de Derecho internacional privado que regula las cuestiones jurídicoreales, así como otros tipos de garantías, es el de la Ley del Estado de matrícula o registro o la "Ley del pabellón", que ha permitido solucionar en teoría el problema de la continuidad de los derechos de garantía, al atribuir a dichos bienes una localización ficticia permanente, que pueda asegurar el reconocimiento de los derechos que puedan gravar a dichos bienes en los territorios de muchos Estados $^{29}$. Sin embargo, también se plantea el problema de que en ocasiones, el Estado de registro o de matrícula de la aeronave - no sucede lo mismo con los buques- no es el Estado en el que la aerolínea tiene

${ }^{24}$ R. Goode, Legal Problems of Credit and Securities, $2^{\mathrm{a}}$ ed., Sweet \& Maxwell, Londres, 1988, pp. 13 y ss.

${ }_{25} \mathrm{La}$ influencia del Derecho norteamericano en dichos principios, en concreto del art. 9 del Uniform Commercial Code, es manifiesta y así ha sido reconocido por algunos autores. Estos principios están recogidos en los modelos de legislación promovidos por los bancos de desarrollo en América Latina y en Asia, y también en Europa. De hecho, la difusión de estos principios ha influido en las legislaciones más reticientes a una reforma. Así, el Derecho francés, parece por ejemplo integrar en parte estos principios en la disposición de 23 de marzo de 2006, al dedicarse principalmente a la prenda sin desplazamiento de la posesión y al pacto comisorio (B. Poulain, "L'impact economique du Droit Privé International sur le financement des aeronefs civils. La Convention UNIDROIT du 16 novembre 2001", Revue Française de Droit Aérien et Spatial, Vol. 238, núm. 2, abril - junio, 2006, pp. 106-7). Sin embargo, en Derecho español, mientras que la prenda sin desplazamiento se contempla en la Ley de 16 de diciembre de 1954, sobre Hipoteca Mobiliaria y Prenda sin desplazamiento (BOE núm. 352, 18 diciembre 1954), el pacto comisorio está prohibido.

${ }^{26}$ En Derecho español quien recoge este principio es el art. 10.1 del Código Civil.

27 F.-J. Gómez Gálligo/ I. Heredia Cervantes, "El convenio de Ciudad del Cabo y su protocolo sobre bienes de equipo espacial”, Revista Crítica de Derecho Inmobiliario, núm. 731, mayo 2012, p. 1420.

28 Vid. K. KReuZER, "La propriété mobilière en droi international privé", Cours de l'Académie de droit international de La Haye, 1996, pp. 13-317.

${ }^{29}$ En Derecho español, además de los buques y las aeronaves, los medios de transporte por ferrocarril, también están incluidos entre los bienes cuyos derechos reales y demás garantías quedan regulados por la Ley del lugar de su abanderamiento, matrícula o registro (art. 10.2 del Código Civil). Para el reconocimiento de los derechos constituidos conforme a la Ley del Estado de matrícula de la aeronave se creó el Convenio de Ginebra de 1948, del que España no es Estado contratante, pero ha tenido escasa aplicación práctica. Además con el Convenio de Ciudad del Cabo y su Protocolo Aeronáutico el ámbito de aplicación del Convenio de Ginebra ha quedado reducido fundamentalmente a las hipotecas, que prácticamente no se realizan debido a su elevado coste. 
su base de operaciones, es decir, que dichos Estados constituyen "pabellones de complacencia", conforme a cuya Ley se han constituido los derechos de garantía, pero que puede plantear problemas de reconocimiento en el resto de Estados en los que la aeronave opera realmente. Además, existen bienes objeto del Convenio y el Protocolo como son los motores que aunque en algunos Estados son registrados, en otros Estados como es el caso de España, no es obligatoria su inscripción, cuando en realidad tienen una gran importancia económica ${ }^{30}$.

Ningún texto internacional ha planteado un régimen completo para la constitución, la inscripción y la ejecución de una garantía realizada sobre un bien de equipo, como es el aeronáutico, que está siendo explotado en los territorios de más de un Estado. La ausencia de un instrumento de tales características, en un contexto económico en el que las operaciones de puesta a disposición de bienes de equipo móviles, concretamente de tipo aeronáutico, implican que los proveedores de fondos, los fabricantes y los usuarios de estos bienes están en raras circunstancias en el territorio de un mismo Estado, ha sido destacada por el Consejo de Dirección de UNIDROIT, a raíz de adopción de la Convención de Ottawa sobre arrendamiento financiero de 1988.

Existe pues una necesidad jurídica, a la vez que financiera y comercial para que se haya abordado una reglamentación internacional en materia de garantías mobiliarias. Además, los autores que han configurado el Convenio y su Protocolo Aeronáutico han condicionado deliberadamente la entrada en vigor de ambos instrumentos a un número pequeño de ratificaciones, para que se aplique lo más rápidamente posible con el objeto de beneficiar a aquellas transacciones que los primeros Estados que lo ratifiquen hayan decidido favorecer ${ }^{31}$. Por lo tanto, se le ha dado al Convenio y su Protocolo Aeronáutico cierta flexibilidad al establecer un sistema complejo de declaraciones, que cada Estado tiene que realizar cuando se decida a ratificarlos ${ }^{32}$. Con el objetivo de conciliar eficacia comercial y sensibilidad a las diferentes tradiciones jurídicas, el Convenio y su Protocolo cuenta con 36 posibles declaraciones, que les permiten a los Estados contratantes poder conseguir el mejor compromiso entre las exigencias de los inversores aeronáuticos y sus tradiciones jurídicas ${ }^{33}$.

5. Por lo tanto, el Convenio y su Protocolo Aeronáutico con el objetivo de dar confianza a futuros inversores que deseen conceder créditos en el sector aeronáutico y reducir a la vez los costes financieros de las compañías, normalmente las aerolíneas, que reciben dicha financiación, contempla una serie de materias, entre las que se deben destacar: a) la creación de una garantía internacional que deberá ser reconocida en todos los Estados contratantes; b) el desarrollo de una serie de medidas a las que puede optar el acreedor o acreedores en caso de incumplimiento del deudor, así como una serie de medidas provisionales cuando existe una prueba de tal incumplimiento; c) la elaboración de unas normas de competencia judicial internacional y de Ley aplicable para que el acreedor pueda reclamar dichas medidas ante el incumplimiento, además de unas reglas en caso de insolvencia; d) el establecimiento de un registro electrónico internacional en el que inscribir las garantías internacionales constituidas conforme al Convenio y su Protocolo Aeronáutico, con la finalidad de que sea oponible frente a terceros, a la vez que permitirá al acreedor que su garantía tenga prioridad sobre otra garantía inscrita con posterioridad, o en general, sobre toda garantía no inscrita, ya sea anterior o posterior, así como sobre el administrador de la insolvencia del deudor.

El Convenio de Ciudad del Cabo y su Protocolo son básicamente instrumentos de derecho sustantivo, con lo cual como norma general no se acude a los ordenamientos internos de los Estados, ni por

30 B. Poulain, "L'impact economique du Droit Privé International sur le financement des aeronefs civils. La Convention UNIDROIT du 16 novembre 2001", Revue Française de Droit Aérien et Spatial, Vol. 238, núm. 2, abril - junio, 2006, p. 108.

31 Mientras que el Convenio exige sólo tres ratificaciones para su entrada en vigor, el Protocolo Aeronáutico exige ocho, que tampoco son un número muy elevado (vid J. Wool/ L. CLARK, "Entry into force of transactional private law treaties affecting aviation: case estudy proposed Unidroit/ICAO Convention as applied to aircraft equipment", Journal of Air Law and Commerce, fall 2001, pp. 1403-20).

32 En este sentido, en la página del $A W G$ donde el tema principal de estudio es el Convenio y su Protocolo Aeronáutico, el primer apartado se denomina "Ratification and Implementation of the Cape Town Convention" y otro de sus apartados tiene por título "Declarations under the Cape Town Convention", ambos disponibles en línea en http://www.awg.aero/projects/capetownconvention (consultado el 16 de noviembre del 2016).

33 B. Poulain, "L'impact economique du Droit Privé International sur le financement des aeronefs civils. La Convention UNIDROIT du 16 novembre 2001”, Revue Française de Droit Aérien et Spatial, Vol. 238, núm. 2, abril - junio, 2006 , p. 115. 
lo tanto a las normas de conflicto estatales, salvo algunas excepciones en que el Convenio se remita a ellas $^{34}$. En definitiva, como un único instrumento que son, recogen un conjunto de reglas uniformes relativas a la constitución, eficacia y rango de las garantías respecto de los bienes de equipo aeronáuticos, en principio respecto de un deudor situado en un Estado contratante, basadas en un sistema de Registro Internacional. Pero el art. IV.1 del Protocolo establece que, además del lugar de situación del deudor, el Convenio se aplicará cuando el Estado contratante sea el Estado de matrícula de un helicóptero sobre el que se ha constituido una garantía o el de una aeronave sobre cuya célula se ha constituido una garantía ${ }^{35}$. Este es un criterio adicional y alternativo al recogido en el art. 3 del Convenio, por lo que si el deudor está situado en un Estado contratante, no es relevante que el Estado de Registro no sea Estado contratante, y a la inversa. Sin embargo, en cuanto a los motores de aeronaves, el factor de conexión alternativo para la aplicación del "Sistema de Ciudad del Cabo" no puede ser utilizado con respecto a dichos objetos, puesto que los motores no poseen Estado de matrícula en el sentido del Convenio de Chicago de $1944^{36}$.

6. En cuanto a las reglas de interpretación del Convenio están recogidas en los arts. 5 y 6 del texto internacional, de manera que en el art. 5.1 se establece la interpretación autónoma del Convenio, al recoger principios similares a otros textos internacionales como es la Convención de Viena de 1980 sobre Compraventa Internacional de Mercaderías ${ }^{37}$.

Además de esta interpretación autónoma y uniforme del Convenio, en su art. 5.2 establece un método para la resolución de lagunas, de manera análoga al art. 7.2 de la Convención de Viena de 1980, de manera que las cuestiones no resueltas expresamente por el Convenio, no pueden resolverse internamente por analogía ${ }^{38}$. El precepto señala que en primer lugar se deberá acudir a los principios generales en los que se basa el Convenio y, en su defecto, a la Ley aplicable, en virtud de las normas de Derecho internacional privado del tribunal que conoce del caso.

34 Art. 5.2 Convenio relativo a garantías internacionales sobre elementos de equipo móvil. Decisión del Consejo núm. 2009/370/CE, de 6 de abril de 2009, relativa a la adhesión de la Comunidad Europea al Convenio relativo a garantías internacionales sobre elementos de equipo móvil y su Protocolo sobre cuestiones específicas de elementos de equipo aeronáutico, adoptados conjuntamente en Ciudad del Cabo el 16 de noviembre del 2001, DO núm. L 121, 15 mayo 2009; art. 5.2 Instrumento de Adhesión de España al Convenio relativo a garantías internacionales sobre elementos de equipo móvil, hecho en Ciudad del Cabo el 16 de noviembre de 2001, BOE núm. 238, 4 octubre 2013.

35 También se especifica que cuando esa inscripción se realice para cumplir un acuerdo de matriculación de la aeronave, la inscripción se considerará efectuada en la fecha del acuerdo (art. IV.1 Protocolo sobre cuestiones específicas de los elementos de equipo aeronáutico, del Convenio relativo a garantías internacionales sobre elementos de equipo móvil. Decisión del Consejo núm. 2009/370/CE, de 6 de abril de 2009, relativa a la adhesión de la Comunidad Europea al Convenio relativo a garantías internacionales sobre elementos de equipo móvil y su Protocolo sobre cuestiones específicas de elementos de equipo aeronáutico, adoptados conjuntamente en Ciudad del Cabo el 16 de noviembre del 2001, DO núm. L 121, 15 mayo 2009).

36 R. Goode, Official Commentary. Revised Edition. Convention on International Interests in Mobile Equipment and Protocol Thereto on Matters Specific to Aircraft Equipment, Unidroit, Roma, 2008, p. 312.

37 Este precepto dice textualmente: "En la interpretación del presente Convenio se tendrán en cuenta sus fines, tal como se enuncian en el preámbulo, su carácter internacional y la necesidad de promover su aplicación uniforme y previsible." (art. 5.1 Convenio relativo a garantías internacionales sobre elementos de equipo móvil. Decisión del Consejo núm. 2009/370/CE, de 6 de abril de 2009, relativa a la adhesión de la Comunidad Europea al Convenio relativo a garantías internacionales sobre elementos de equipo móvil y su Protocolo sobre cuestiones específicas de elementos de equipo aeronáutico, adoptados conjuntamente en Ciudad del Cabo el 16 de noviembre del 2001, DO núm. L 121, 15 mayo 2009; art. 5.1 Instrumento de Adhesión de España al Convenio relativo a garantías internacionales sobre elementos de equipo móvil, hecho en Ciudad del Cabo el 16 de noviembre de 2001, BOE núm. 238, 4 octubre 2013). Con respecto a la Convención de Viena existe una diferencia en la redacción, porque se ha cambiado "la buena fe" por "la necesidad de promover su aplicación previsible y uniforme" (art. 7.1 Instrumento de Adhesión de España a la Convención de Naciones Unidas de 1980 sobre los Contratos de Compraventa Internacional de Mercaderías, hecha en Viena el 11 de abril de 1980, BOE núm. 26, 30 enero 1991; corrección de errores BOE núm. 282, 22 noviembre 1996).

38 Este precepto dice textualmente: "Las cuestiones relativas a las materias regidas por el presente Convenio y que no estén expresamente resueltas en el mismo se resolverán de conformidad con los principios generales en los que se funda o, a falta de tales principios, de conformidad con la ley aplicable." (art. 5.2 Convenio relativo a garantías internacionales sobre elementos de equipo móvil. Decisión del Consejo núm. 2009/370/CE, de 6 de abril de 2009, relativa a la adhesión de la Comunidad Europea al Convenio relativo a garantías internacionales sobre elementos de equipo móvil y su Protocolo sobre cuestiones específicas de elementos de equipo aeronáutico, adoptados conjuntamente en Ciudad del Cabo el 16 de noviembre del 2001, DO núm. L 121, 15 mayo 2009; art. 5.2 Instrumento de Adhesión de España al Convenio relativo a garantías internacionales sobre elementos de equipo móvil, hecho en Ciudad del Cabo el 16 de noviembre de 2001, BOE núm. 238, 4 octubre 2013). 
Por lo que respecta a los principios generales, en el Convenio no se mencionan, pero de los fines señalados en el preámbulo y de sus disposiciones se pueden deducir los siguientes: utilidad o sentido práctico, autonomía de la voluntad, previsibilidad, transparencia y sensibilidad a las tradiciones legales nacionales ${ }^{39}$. Este último principio se articula a través de un conjunto de reservas y declaraciones, pero lo que es más importante, la calificación de si se trata de uno de los tipos de contratos establecidos en el Convenio: contrato constitutivo de garantía, de arrendamiento o compraventa con reserva de dominio, que crea o prevé la garantía internacional sobre bienes aeronáuticos, se realiza conforme a la legislación nacional. Esta cuestión puede no parecer relevante en principio, pero la calificación del contrato que genera la garantía internacional en uno de los tipos mencionados, determina las medidas que se pueden tomar en caso de incumplimiento del deudor, en virtud del Convenio ${ }^{40}$. Tales medidas a adoptar por la otra parte contratante en caso de incumplimiento del deudor, se detallan en los arts. 8 y 9 del Convenio, así como en los art. IX y XIII del Protocolo Aeronáutico, además de las medidas provisionales que también se contemplan.

En cuanto a la ley aplicable, el Convenio establece expresamente que todas las referencias a la Ley aplicable, se entienden realizadas a las normas de derecho interno o sustantivo de la Ley aplicable designada por las normas de conflicto del tribunal que conoce del asunto ${ }^{41}$. En consecuencia, el Convenio no contempla la posibilidad de ningún tipo de reenvío, ni de retorno o de primer grado, ni de segundo grado.

Además, el Convenio establece también respecto de la Ley aplicable una disposición en el supuesto de que se produjese una remisión a ordenamientos plurilegislativos. En estos casos, si es posible determinar la unidad territorial pertinente, será la Ley de dicha unidad territorial la que sea de aplicación. Pero en caso contrario, se acudirá a la Ley de ese Estado para establecer la unidad territorial cuyas normas regirán. Ahora bien, si tampoco existiese ninguna regulación al respecto, se aplicará la Ley de la unidad territorial con la cual el supuesto presente los vínculos más estrechos ${ }^{42}$.

Por último, el Convenio de Ciudad del Cabo no se ha empezado a aplicar hasta que no ha entrado en vigor el Protocolo Aeronáutico y la aplicación de las reglas convencionales debe realizarse siempre de la forma contemplada en el Protocolo. Así que en caso de discrepancia entre ambos textos prevalece el Protocolo Aeronáutico ${ }^{43}$.

39 Para un mayor desarrollo de estos principios vid. R. Goode, Official Commentary. Revised Edition. Convention on International Interests in Mobile Equipment and Protocol Thereto on Matters Specific to Aircraft Equipment, Unidroit, Roma, 2008, pp. 18 y 173; T. RODRÍGUEz de las HeRAs Ballell, Las garantías mobiliarias sobre equipo aeronáutico en el comercio internacional. El Convenio de Ciudad del Cabo y su protocolo, Marcial Pons, Madrid, 2012, p. 31.

40 Art. 2.4 Convenio relativo a garantías internacionales sobre elementos de equipo móvil. Decisión del Consejo núm. 2009/370/CE, de 6 de abril de 2009, relativa a la adhesión de la Comunidad Europea al Convenio relativo a garantías internacionales sobre elementos de equipo móvil y su Protocolo sobre cuestiones específicas de elementos de equipo aeronáutico, adoptados conjuntamente en Ciudad del Cabo el 16 de noviembre del 2001, DO núm. L 121, 15 mayo 2009; art. 2.4 Instrumento de Adhesión de España al Convenio relativo a garantías internacionales sobre elementos de equipo móvil, hecho en Ciudad del Cabo el 16 de noviembre de 2001, BOE núm. 238, 4 octubre 2013.

${ }^{41}$ Art. 5.3 Convenio relativo a garantías internacionales sobre elementos de equipo móvil. Decisión del Consejo núm. 2009/370/CE, de 6 de abril de 2009, relativa a la adhesión de la Comunidad Europea al Convenio relativo a garantías internacionales sobre elementos de equipo móvil y su Protocolo sobre cuestiones específicas de elementos de equipo aeronáutico, adoptados conjuntamente en Ciudad del Cabo el 16 de noviembre del 2001, DO núm. L 121, 15 mayo 2009; art. 5.3 Instrumento de Adhesión de España al Convenio relativo a garantías internacionales sobre elementos de equipo móvil, hecho en Ciudad del Cabo el 16 de noviembre de 2001, BOE núm. 238, 4 octubre 2013.

42 Art. 5.4 Convenio relativo a garantías internacionales sobre elementos de equipo móvil. Decisión del Consejo núm. 2009/370/CE, de 6 de abril de 2009, relativa a la adhesión de la Comunidad Europea al Convenio relativo a garantías internacionales sobre elementos de equipo móvil y su Protocolo sobre cuestiones específicas de elementos de equipo aeronáutico, adoptados conjuntamente en Ciudad del Cabo el 16 de noviembre del 2001, DO núm. L 121, 15 mayo 2009; art. 5.4 Instrumento de Adhesión de España al Convenio relativo a garantías internacionales sobre elementos de equipo móvil, hecho en Ciudad del Cabo el 16 de noviembre de 2001, BOE núm. 238, 4 octubre 2013.

43 Art. 6 Convenio relativo a garantías internacionales sobre elementos de equipo móvil. Decisión del Consejo núm. 2009/370/CE, de 6 de abril de 2009, relativa a la adhesión de la Comunidad Europea al Convenio relativo a garantías internacionales sobre elementos de equipo móvil y su Protocolo sobre cuestiones específicas de elementos de equipo aeronáutico, adoptados conjuntamente en Ciudad del Cabo el 16 de noviembre del 2001, DO núm. L 121, 15 mayo 2009; art. 6 Instrumento de Adhesión de España al Convenio relativo a garantías internacionales sobre elementos de equipo móvil, hecho en Ciudad del Cabo el 16 de noviembre de 2001, BOE núm. 238, 4 octubre 2013. 


\section{EI Registro Internacional}

7. El Registro Internacional y la creación del concepto de "garantía internacional" forman las dos piezas claves del "Sistema de Ciudad del Cabo". Sin embargo, para empezar, no coincide el carácter internacional del Registro con la naturaleza internacional de la garantía. Esto se debe a que no todas las garantías o derechos que tienen acceso al Registro Internacional son garantías internacionales ${ }^{44}$. Se pueden inscribir en el mismo, avisos de garantías nacionales y otros derechos o garantías no contractuales que serán tratados como garantías internacionales cuando así lo declare el Estado contratante ${ }^{45}$. Por lo tanto, el acceso al Registro Internacional no transforma el derecho o garantía inscrita en garantía internacional, porque la inscripción no es un requisito para la creación de una garantía internacional, sino que es una condición para que mantenga la prioridad frente a otras garantías concurrentes, y en supuestos de insolvencia del deudor ${ }^{46}$. Además habrá garantías nacionales, es decir, que se constituyan conforme al Derecho nacional, que a través de los correspondientes avisos de garantía nacional, tengan los mismos efectos que las garantías internacionales, así que convivirán ambas. Dicha garantía nacional, tras su inscripción en el Registro como aviso de garantía nacional, conferirá a su titular derechos más fuertes que la garantía nacional.

\section{Características}

8. El "Sistema de Ciudad del Cabo" se sustenta en un esquema registral propio, de manera que cada uno de los Protocolos cuenta con su propio Registro Internacional. A su vez, cada Registro está gestionado por un Registrador, que opera bajo la supervisión de una Autoridad supervisora ${ }^{47}$. El Registro Internacional para elementos de equipo aeronáutico está en funcionamiento desde la entrada en vigor del Protocolo Aeronáutico el 1 de marzo del 2006. La Autoridad supervisora, que es la OACI (Organization Aviation Civil International), es la encargada de nombrar al Registrador del Registro Internacional de garantías sobre objetos Aeronáutico ${ }^{48}$. Además, la OACI tiene otras competencias, como la aprobación de normas de carácter más técnico, que entraron en vigor el mismo día del Protocolo, y que son las Normas del Registro Internacional (Regulations for the International Registry) y los Procedimientos del Registro Internacional (International Registry Procedures) ${ }^{49}$.

Pues bien, el Registrador en la actualidad es la compañía irlandesa Aviareto, que fue seleccionada en 2004 como encargada de dicho Registro Internacional y que sigue desempeñando esta función ac-

\footnotetext{
${ }^{44} \mathrm{Al}$ respecto de lo que se considera garantía inscrita, dice el art. 1.cc Convenio: "Una garantía internacional, un derecho o una garantía no cotractual susceptibles de inscripción o una garantía nacional especificada en un aviso de garantía nacional inscrita con arreglo al Capitulo V'.

45 Art. 16 Convenio relativo a garantías internacionales sobre elementos de equipo móvil. Decisión del Consejo núm. 2009/370/CE, de 6 de abril de 2009, relativa a la adhesión de la Comunidad Europea al Convenio relativo a garantías internacionales sobre elementos de equipo móvil y su Protocolo sobre cuestiones específicas de elementos de equipo aeronáutico, adoptados conjuntamente en Ciudad del Cabo el 16 de noviembre del 2001, DO núm. L 121, 15 mayo 2009.

46 T. Rodríguez de las Heras Ballell, Las garantías mobiliarias sobre equipo aeronáutico en el comercio internacional. El Convenio de Ciudad del Cabo y su protocolo, Marcial Pons, Madrid, 2012, p. 160.

47 Art. 17 Convenio relativo a garantías internacionales sobre elementos de equipo móvil. Decisión del Consejo núm. 2009/370/CE, de 6 de abril de 2009, relativa a la adhesión de la Comunidad Europea al Convenio relativo a garantías internacionales sobre elementos de equipo móvil y su Protocolo sobre cuestiones específicas de elementos de equipo aeronáutico, adoptados conjuntamente en Ciudad del Cabo el 16 de noviembre del 2001, DO núm. L 121, 15 mayo 2009.

48 El nombramiento de la OACI como Autoridad supevisora se produjo por una Resolución, en la Conferencia diplomática en la que se adoptó el Convenio y su Protocolo Aeronáutico, en virtud del art. XVII.1 del Protocolo. Para examinar el texto completo de dicha Resolución (Resolution $n^{\circ}$ 2) vid. R. Goode, Official Commentary. Revised Edition. Convention on International Interests in Mobile Equipment and Protocol Thereto on Matters Specific to Aircraft Equipment, Unidroit, Roma, 2008, pp. 511-512.

49 Para consultar la tercera edición de las Normas y Procedimientos del Registro Internacional, del año 2008, vid. R. GoodE, Official Commentary. Revised Edition. Convention on International Interests in Mobile Equipment and Protocol Thereto on Matters Specific to Aircraft Equipment, Unidroit, Roma, 2008, pp. 421-459. La última edición de las Normas y Procedimientos del Registro Internacional se realizó en el año 2014 y se corresponde con la sexta edición. Dichas normas están disponibles en línea en http://www.icao.int/publications/Documents/9864_6ed_es.pdf (consultado el 16 de noviembre de 2016).
} 
tualmente ${ }^{50}$. Dicho Registro es un recurso completamente electrónico, disponible en la dirección https:// www.internationalregistry.aero/ir-web/, que tiene un carácter centralizado para su consulta universal on-line.

9. En cuanto a las características fundamentales del Registro Internacional son: a) es un registro solamente publicístico, es decir, en el que no se realiza ninguna calificación; b) el objeto de inscripción no es el deudor, sino el bien, en definitiva, se lleva a cabo la ordenación del registro por sistema de folio real; c) permite al acreedor preservar su rango por prioridad cronológica, siendo oponible frente a terceros; otorga prioridad frente a las garantías que no hayan sido inscritas en el Registro internacional, ni estén cubiertas por una declaración realizada por un Estado contratante en virtud del artículo 39; y se pueden inscribir los pactos de cesión y de subrogación, así como de subordinación de rango de las garantías; d) los efectos de la inscripción se producen desde el momento en que puede ser consultada.

Los criterios de consulta de los bienes aeronáuticos: células de aeronaves, motores de aeronaves y helicópteros, serán el nombre del fabricante, el número de serie del fabricante y la designación del modelo genérico, además de la información necesaria para su identificación ${ }^{51}$.

10. Cada Estado contratante podrá designar una entidad o varias dentro de su territorio como puntos de acceso por medio de los cuales se transmitirá o se podrá transmitir al Registro Internacional la información necesaria para su inscripción, tal y como señala el art. XIX.1 del Protocolo Aeronáutico ${ }^{52}$. De manera, que si un Estado contratante designa un punto de acceso para poder transmitir la información al objeto de realizar la inscripción, dicho Estado contratante podrá establecer los requisitos, si los hubiera, para que esta información se transmita al Registro Internacional ${ }^{53}$.

En este sentido, el art. 12.1 de las Normas del Registro Internacional señala que cada Estado podrá designar un punto o varios puntos de acceso de conformidad con el art. XIX.1. Ahora bien, cada Estado contratante puede optar por designar puntos de acceso autorizantes o puntos de acceso directos. Los puntos de acceso autorizantes de un Estado contratante transmitirán o podrán autorizar la transmisión al Registro Internacional de la información necesaria para la inscripción de un derecho o garantía. Mientras que a través de los puntos de acceso directos de un Estado contratante se transmitirá o se podrá transmitir la información directamente al Registro Internacional para la inscripción de un derecho o garantía.

Un Estado contratante sólo puede designar que los puntos de acceso sean obligatorios en el caso de que se trate de una inscripción relativa a las células de aeronaves y a los helicópteros, de los cuales dicho Estado contratante es el Estado de matrícula ${ }^{54}$. Esta obligatoriedad no se produce en el caso de los

${ }^{50}$ La compañía Aviareto con sede en Dublín fue inicialmente nombrada para encargarse del funcionamiento del Registro Internacional desde la fecha de entrada en vigor del Protocolo durante un período de cinco años, a partir del cual será la OACI la que prorrogará el nombramiento por períodos de la misma duración o bien nombrará otro Registrador (art. XVII.5 Protocolo sobre cuestiones específicas de los elementos de equipo aeronáutico, del Convenio relativo a garantías internacionales sobre elementos de equipo móvil. Decisión del Consejo núm. 2009/370/CE, de 6 de abril de 2009, relativa a la adhesión de la Comunidad Europea al Convenio relativo a garantías internacionales sobre elementos de equipo móvil y su Protocolo sobre cuestiones específicas de elementos de equipo aeronáutico, adoptados conjuntamente en Ciudad del Cabo el 16 de noviembre del 2001, DO núm. L 121, 15 mayo 2009).

${ }^{51}$ Art. XX Protocolo sobre cuestiones específicas de los elementos de equipo aeronáutico, del Convenio relativo a garantías internacionales sobre elementos de equipo móvil. Decisión del Consejo núm. 2009/370/CE, de 6 de abril de 2009, relativa a la adhesión de la Comunidad Europea al Convenio relativo a garantías internacionales sobre elementos de equipo móvil y su Protocolo sobre cuestiones específicas de elementos de equipo aeronáutico, adoptados conjuntamente en Ciudad del Cabo el 16 de noviembre del 2001, DO núm. L 121, 15 mayo 2009.

52 En este sentido, el art. 18 del Convenio establece que es el Protocolo y las Normas y Procedimientos del Registro Internacional los que señalen los requisitos de inscripción de las garantías.

53 Art. 18.5 Convenio relativo a garantías internacionales sobre elementos de equipo móvil. Decisión del Consejo núm. 2009/370/CE, de 6 de abril de 2009, relativa a la adhesión de la Comunidad Europea al Convenio relativo a garantías internacionales sobre elementos de equipo móvil y su Protocolo sobre cuestiones específicas de elementos de equipo aeronáutico, adoptados conjuntamente en Ciudad del Cabo el 16 de noviembre del 2001, DO núm. L 121, 15 mayo 2009.

54 Art. 12.2 Normas del Registro Internacional (R. Goode, Official Commentary. Revised Edition. Convention on International Interests in Mobile Equipment and Protocol Thereto on Matters Specific to Aircraft Equipment, Unidroit, Roma, 2008, p. 436). 
motores, porque estos no están sujetos a la inmatriculación prevista en el Convenio de Chicago de 1944. En este mismo sentido, el art. XIX.2 del Protocolo señala que la inscripción de los motores a través de los puntos de acceso nacionales únicamente se podrá permitir, pero no imponer.

Se debe tener en cuenta que mediante de los puntos de acceso nacionales no se podrá realizar la transmisión de la información necesaria para la inscripción, cuando se trate de la inscripción de avisos de garantías nacionales o de derechos o garantías no contractuales susceptibles de inscripción que estén sometidas a las Leyes de un Estado diferente al que pertenece el punto de acceso ${ }^{55}$. Si no se trata de uno de estos casos señalados, el punto de acceso nacional puede designarse para realizar cualquier tipo de asiento previsto por el Registro, o para la cancelación o la modificación de inscripciones ya realizadas ${ }^{56}$.

11. Existen sin embargo, problemas derivados de las discordancias entre las disposiciones sustantivas del "Sistema de Ciudad de Cabo" con respecto a las cuestiones formales asociadas al Registro Internacional. Pero la mayor fuente de discusión deriva del propio sistema organizativo del Convenio, como consecuencia de la posibilidad otorgada por el Convenio, de que cada Estado contratante designe un "punto de acceso nacional" 57 . Por lo tanto, el Registro Internacional que responde a un modelo centralizado e internacional, puede verse distorsionado por los efectos de los "puntos de acceso nacionales", si las entidades designadas como puntos de acceso nacionales establecen condiciones de acceso, transmisión o legitimación, que provoquen la disparidad nacional ${ }^{58}$.

Al respecto el Convenio establece que no se permitirá ninguna acción que deniegue el acceso al Registro de manera injustificada ${ }^{59}$. De hecho, en opinión de algunos autores los requisitos de Derecho interno, que deben respetarse de conformidad con el art. 18.5 del Convenio, no deben excederse de aquellos requisitos y procedimientos a los que el "Sistema de Ciudad del Cabo" somete al Registro Internacional, así como aquellos requisitos de naturaleza jurídico-pública que están fuera del ámbito de aplicación del Convenio y su Protocolo Aeronáutico, tales como la imposición de tasas o aranceles ${ }^{60}$. En consecuencia, cualquier otro requisito debería ser descartado, aunque la realidad es bien diferente.

12. Pero además del problema señalado, se plantean una serie de cuestiones cuando se pretende inscribir un derecho o garantía en el Registro Internacional, no del todo resueltas por las disposiciones del "Sistema de Ciudad del Cabo" y la regulación del Registro Internacional. En primer lugar, en cuanto al ámbito de aplicación personal del Convenio y su Protocolo Aeronáutico, si el deudor está situado en un Estado contratante, la garantía internacional constituida puede acceder vía telemática al Registro Internacional, con independencia de que el Estado de registro sea o no un Estado contratante. Sin embargo, se debe tener en cuenta que si el Estado contratante de registro de la célula de aeronave o del helicóptero, establece un punto de acceso nacional, deben respetarse los requisitos para su incripción en el Registro Internacional a través

55 Art. XIX.1 Protocolo sobre cuestiones específicas de los elementos de equipo aeronáutico, del Convenio relativo a garantías internacionales sobre elementos de equipo móvil. Decisión del Consejo núm. 2009/370/CE, de 6 de abril de 2009, relativa a la adhesión de la Comunidad Europea al Convenio relativo a garantías internacionales sobre elementos de equipo móvil y su Protocolo sobre cuestiones específicas de elementos de equipo aeronáutico, adoptados conjuntamente en Ciudad del Cabo el 16 de noviembre del 2001, DO núm. L 121, 15 mayo 2009.

56 I. Heredia Cervantes, "Análisis de la adhesión de España al Protocolo Aeronáutico del Convenio de Ciudad del Cabo", La Ley mercantil, núm. 21, 1 enero 2016, p. 7.

57 Art. XIX.1 Protocolo sobre cuestiones específicas de los elementos de equipo aeronáutico, del Convenio relativo a garantías internacionales sobre elementos de equipo móvil. Decisión del Consejo núm. 2009/370/CE, de 6 de abril de 2009, relativa a la adhesión de la Comunidad Europea al Convenio relativo a garantías internacionales sobre elementos de equipo móvil y su Protocolo sobre cuestiones específicas de elementos de equipo aeronáutico, adoptados conjuntamente en Ciudad del Cabo el 16 de noviembre del 2001, DO núm. L 121, 15 mayo 2009.

58 T. Rodríguez de las Heras Ballell, Las garantías mobiliarias sobre equipo aeronáutico en el comercio internacional. El Convenio de Ciudad del Cabo y su protocolo, Marcial Pons, Madrid, 2012, p. 161.

59 Art. 26 Convenio relativo a garantías internacionales sobre elementos de equipo móvil. Decisión del Consejo núm. 2009/370/CE, de 6 de abril de 2009, relativa a la adhesión de la Comunidad Europea al Convenio relativo a garantías internacionales sobre elementos de equipo móvil y su Protocolo sobre cuestiones específicas de elementos de equipo aeronáutico, adoptados conjuntamente en Ciudad del Cabo el 16 de noviembre del 2001, DO núm. L 121, 15 mayo 2009.

60 I. Heredia Cervantes, "Análisis de la adhesión de España al Protocolo Aeronáutico del Convenio de Ciudad del Cabo", La Ley mercantil, núm. 21, 1 enero 2016, p. 8. 
de dicho punto de acceso nacional ${ }^{61}$. Por otro lado, si el deudor no está situado en un Estado contratante y no se puede crear la correspondiente garantía internacional, pero el Estado de registro es un Estado contratante con punto de acceso nacional, se acudiría a él para el acceso al Registro internacional del resto de garantías o derechos distintos de la garantía internacional previstos en el Convenio y su Protocolo Aeronáutico.

En segundo lugar, la transmisión a través de los puntos de acceso nacionales de las células de aeronaves y de los helicópteros, no es obligatoria para la inscripción de la garantía con respecto a los motores de aeronaves -ya que en todos los Estados no se les asigna un número de registro o matrícula, a diferencia de lo que sucede con las células o los helicópteros-, aunque se puede realizar a través de ellos $^{62}$. Por lo tanto, habrá Estados que hagan la inscripción de los motores en el Registro Internacional a través de los puntos de acceso nacionales, y otros Estados que lo hagan directamente a través del Registro Internacional, de manera opcional.

En tercer lugar, no se puede designar un punto de acceso nacional, para la inscripción de avisos de garantías nacionales o de garantías o derechos no contractuales inscribibles constituidos bajo las Leyes de otro Estado ${ }^{63}$. En definitiva, un Estado contratante sólo puede realizar a través de su punto de acceso nacional, la inscripción de los avisos de garantías nacionales o derechos o garantías contemplados en el art. 40 del Convenio cuando se han constituido bajo su Derecho nacional; lo cual tiene su lógica.

En cuarto lugar, cada Estado contratante que designe uno o varios puntos de acceso nacionales, deberá establecer si se trata de un punto de acceso directo o autorizante, de lo cual tendrá conocimiento el Registrador ${ }^{64}$. Así pues, si un Estado contratante designa un punto de acceso autorizante para inscribir una garantía sobre una célula de aeronave o un helicóptero matriculados en dicho Estado contratante, pero la inscripción no respeta el procedimiento establecido, tal registro no será válido y el Registrador advertirá de ello al usuario mediante un mensaje electrónico ${ }^{65}$. De la misma manera, que si un Estado contratante ha establecido que la inscripción de las garantías sobre las células de las aeronaves o los helicópteros se realice obligatoriamente a través de un punto de acceso directo, pero no se efectúa a través del mismo, el Registrador avisará al usuario de la forma señalada. Sin embargo, en el caso de los motores como no es obligatoria la inscripción de su garantía o derecho a través del punto de acceso nacional designado, así que se puede optar o bien por realizar dicha inscripción a través del punto de acceso nacional, ya sea autorizante o directo, o bien directamente a través del Registro Internacional.

13. La razón fundamental de la decisión de un Estado de designar una entidad en su territorio como punto de acceso nacional es la de mantener el control sobre las condiciones de inscripción de operaciones que se venían registrando en su territorio por su vinculación con el mismo. Sin embargo, de los Estados que se han adherido al Convenio y a su Protocolo, sólo ocho han hecho la declaración del artículo XIX del Protocolo, designando puntos de acceso nacionales, entre ellos China, Emiratos Árabes

${ }^{61}$ Art. 12.1 Normas del Registro Internacional (R. Goode, Official Commentary. Revised Edition. Convention on International Interests in Mobile Equipment and Protocol Thereto on Matters Specific to Aircraft Equipment, Unidroit, Roma, 2008, p. 436).

62 Art. XIX.2 Protocolo sobre cuestiones específicas de los elementos de equipo aeronáutico, del Convenio relativo a garantías internacionales sobre elementos de equipo móvil. Decisión del Consejo núm. 2009/370/CE, de 6 de abril de 2009, relativa a la adhesión de la Comunidad Europea al Convenio relativo a garantías internacionales sobre elementos de equipo móvil y su Protocolo sobre cuestiones específicas de elementos de equipo aeronáutico, adoptados conjuntamente en Ciudad del Cabo el 16 de noviembre del 2001, DO núm. L 121, 15 mayo 2009.

63 Art. XIX.1 Protocolo sobre cuestiones específicas de los elementos de equipo aeronáutico, del Convenio relativo a garantías internacionales sobre elementos de equipo móvil. Decisión del Consejo núm. 2009/370/CE, de 6 de abril de 2009, relativa a la adhesión de la Comunidad Europea al Convenio relativo a garantías internacionales sobre elementos de equipo móvil y su Protocolo sobre cuestiones específicas de elementos de equipo aeronáutico, adoptados conjuntamente en Ciudad del Cabo el 16 de noviembre del 2001, DO núm. L 121, 15 mayo 2009.

${ }^{64}$ Art. 12.3 Normas del Registro Internacional (R. Goode, Official Commentary. Revised Edition. Convention on International Interests in Mobile Equipment and Protocol Thereto on Matters Specific to Aircraft Equipment, Unidroit, Roma, 2008, p. 436).

${ }^{65}$ Art. 12.5 Normas del Registro Internacional (R. Goode, Official Commentary. Revised Edition. Convention on International Interests in Mobile Equipment and Protocol Thereto on Matters Specific to Aircraft Equipment, Unidroit, Roma, 2008, p. 436). 
o Estados Unidos ${ }^{66}$. Éste último ha designado al Registro de Aeronaves operado por la Administración Federal de Aviación (FAA-Federal Aviation Administration), como punto de acceso nacional. Pero a diferencia de lo que sucede con el sistema registral español de aeronaves, el Registro de Aeronaves de Estados Unidos, no sólo asigna número de matrícula a las aeronaves de nacionalidad estadounidense, sino que también atribuye ciertos derechos de garantía sobre las aeroanves civiles, los motores y las piezas de repuesto. El problema como ya se ha adelantado es que la FAA además de los requisitos establecidos para el procedimiento de inscripción en el Registro Internacional, solicita toda la documentación exigible por su normativa interna. Por lo tanto, se está desvirtuando la idea principal de que el Registro Internacional debía ser un registro centralizado, sin que cada Estado estableciese los mismos requisitos para la inscripción que los señalados para el acceso a su registro o registros nacionales.

Todos los Estados que han designado puntos de acceso nacionales, los han hecho estableciendo puntos de acceso autorizantes, salvo Emiratos Árabes que designó un punto de acceso directo, pero que tuvo que convertirlo en autorizante por los problemas que le generaba ${ }^{67}$. En este sentido, en el caso de España, el Real Decreto por el que se aprueba el Reglamento de Registro de matriculación de aeronaves civiles, se establece que será el Registro de Bienes Muebles el punto de acceso nacional de la información necesaria para la realización de la inscripción internacional ${ }^{68}$. Así España lo ha señalado también, en la declaración realizada conforme al art. XIX.1 del Protocolo Aeronáutico en el momento de su adhesión, y que será valorada, al estudiar el Registro de Bienes Muebles como punto de acceso autorizante del Registro Internacional.

\section{Tipos de garantías inscribibles}

14. Los arts. 39, 40 y 60 del Convenio, junto con otras disposiciones relacionadas con estos artículos, se refieren a derechos ("rights" en la versión inglesa) o garantías ("interests" en la versión inglesa). Sin embargo, los términos "derechos" o "garantías" no están definidos por el Convenio de Ciudad del Cabo. En general una "garantía" conlleva un derecho in rem sobre un bien, mientras que un "derecho" es un derecho personal a la posesión o control de un bien sobre el cual el titular no tiene una garantía (como es el caso de un derecho de detención de una aeronave por las tasas aeroportuarias) o un derecho al pago, que entraría dentro de la definición de derechos accesorios ${ }^{69}$.

En definitiva, el Convenio contempla la protección de siete categorías de derechos o intereses adquiridos de forma originaria, frente a los adquiridos por cesión o subrogación, y que son:

15. Las garantías internacionales. Están destinadas a ser reconocidas en todos los Estados contratantes y son, por supuesto, la principal categoría de derechos o garantías amparada por el texto convencional. El concepto de garantía internacional adoptado por el "Sistema de Ciudad del Cabo" es un concoepto autónomo, que no se ha tomado de ningún Derecho nacional.

El concepto de "garantía internacional" sobre elementos de equipo móvil es definida en el art. 2.2 del Convenio como: “(...) una garantía constituida con arreglo al artículo 7 sobre un objeto inequívocamente identificable, de una de las categorías de tales objetos enumeradas en el párrafo 3 y designada en el Protocolo: a) Dada por el otorgante en virtud de un contrato constitutivo de garantía; b) correspondiente a una persona que es el vendedor condicional en virtud de un contrato con reserva de dominio; o c) correspondiente a una persona que es el arrendador en virtud de un contrato de arrendamiento (...)”. El art. 41 del Convenio también establece que: “(...) se aplicará a la venta o a la venta

${ }^{66}$ Así el punto de acceso para México es el Registro Aeronáutico Mexicano, para los Emiratos Árabes es la empresa Ince Al Jallaf \& Co (IAJ), para Albania es el Registro de Aeronaves, para China es el Registro de Derechos de Aeronaves, para Brasil es el Registro Aeronáutico Brasileño, para Ucrania es la Administración Estatal de Aviación y para Vietnam es la Administración de Aviación Civil.

67 I. Heredia Cervantes, “Análisis de la adhesión de España al Protocolo Aeronáutico del Convenio de Ciudad del Cabo", La Ley mercantil, núm. 21, 1 enero 2016, p. 8.

68 Disposición adicional sexta RD 384/2015, de 22 de mayo, por el que se aprueba el Reglamento de matriculación de aeronaves civiles, BOE núm. 144, 17 junio 2015.

69 R. Goode, Official Commentary. Revised Edition. Convention on International Interests in Mobile Equipment and Protocol Thereto on Matters Specific to Aircraft Equipment, Unidroit, Roma, 2008, p. 23. 
futura de un objeto de conformidad con lo previsto en el Protocolo y sus modificaciones". El Protocolo amplía el ámbito de aplicación material del sistema de Ciudad del Cabo a los ventas y a los contratos de ventas, aunque a los mismos solamente les son de aplicación algunas disposiciones, en definitiva a las ventas -entendidas éstas como garantías- originadas por contratos de venta se les aplica el Convenio y su Protocolo aeronáutico de forma restrictiva (art. III del Protocolo).

Se deben resaltar tres aspectos de esta definición de garantía internacional realizada por el Convenio: 1) que corresponda a una categoría de objetos como son: "a) células de aeronaves, motores de aeronaves y helicópteros; b) material rodante ferroviario, y c) bienes de equipo espacial" (art. 2.3 del Convenio); 2) que se otorgue en virtud de uno de los contratos anteriormente señalados (art. 2.2 del Convenio); 3) que se cumplan los requisitos formales para la constitución de la garantía conforme al art. 7 del Convenio, entre los que está que el objeto sea perfectamente identificable ${ }^{70}$. Por lo que respecta a la identificación del objeto, es suficiente con conocer el número de serie del fabricante, el nombre del fabricante y la designación del modelo genérico, tal y como establece el art. VII del Protocolo. El resto de requisitos de forma que deben cumplirse son: que el acuerdo se haya realizado por escrito; que exista poder de disposición del objeto aeronáutico por parte del deudor, del vendedor, del vendedor condicional o del arrendador; y que en el caso de los contratos constitutivos de garantías, las obligaciones garantizadas deben estar determinadas en dicho contrato, pero no es necesario establecer una cantidad o una cantidad máxima asegurada (art. 7 del Convenio).

16. Por lo que respecta al contrato de venta, es definido por el Convenio como un contrato para la venta de un objeto por un vendedor a un comprador, dejando claro que no es un contrato de los tres tipos de contratos señalados en el art. 2.2 del Convenio (art. 1.g). Pero además, define a la venta como la transferencia de la propiedad de un objeto en virtud de un contrato de venta (art. 1.gg). Para que se aplique el "Sistema de Ciudad del Cabo" a las ventas es preciso que así lo señale el Protocolo ${ }^{71}$.

Pues bien, es el art. III del Protocolo el que establece que algunas de las disposiciones del "Sistema de Ciudad del Cabo" serán de aplicación a las ventas, así como las equivalencias de ciertos términos, de manera que las referencias a una garantía internacional, una garantía internacional futura, el acreedor y el deudor se entenderán realizadas a una venta, una venta futura, el comprador y el vendedor, respectivamente. También señala que las referencias a un acuerdo que crea o prevé una garantía internacional se entienden realizadas a un contrato de venta. Por lo tanto, es la venta como transmisión de la propiedad el equivalente de la garantía internacional, mientras que el contrato de venta equivaldría a alguno de los contratos antes señalados.

Sin embargo, existen disposiciones del "Sistema de Ciudad del Cabo" que no se aplican a las ventas, para empezar el artículo 2 del Convenio, en el que se aborda la constitución de la garantía internacional, lo cual es lógico porque no es posible que el comprador obtenga una garantía internacional cuando la propiedad del objeto es suya ${ }^{72}$. Las disposiciones del Convenio, en definitiva, que son de

${ }^{70}$ En cuanto a los tres aspectos señalados necesarios para constituir una garantía internacional, la profesora T. RodRíGUEZ de las Heras BaLLELl les atribuye una denominación: elemento objetivo, elemento contractual y elemento formal, haciendo referencia respectivamente al contenido de los arts. 2.3, 2.2 y 7 del Convenio (T. Rodríguez DE LAS Heras Ballell, Las garantías mobiliarias sobre equipo aeronáutico en el comercio internacional. El Convenio de Ciudad del Cabo y su protocolo, Marcial Pons, Madrid, 2012, p. 43).

71 Art. 41 Convenio relativo a garantías internacionales sobre elementos de equipo móvil. Decisión del Consejo núm. 2009/370/CE, de 6 de abril de 2009, relativa a la adhesión de la Comunidad Europea al Convenio relativo a garantías internacionales sobre elementos de equipo móvil y su Protocolo sobre cuestiones específicas de elementos de equipo aeronáutico, adoptados conjuntamente en Ciudad del Cabo el 16 de noviembre del 2001, DO núm. L 121, 15 mayo 2009.

72 Por lo tanto, todo el capítulo III del Convenio, de especial importancia porque se esteblecen las medidas a realizar por el acreedor garantizado, el vendedor con reserva de dominio o el arrendador en caso de incumplimiento, no son de aplicación a la ventas. No es de aplicación el art. 29.3 del Convenio sobre reglas de prioridad, de manera que el comprador de un objeto aeronáutico puede inscribir su garantía. Sin embargo, las ventas no podrían ser objeto de cesión porque no se garantiza ningún derecho de pago sobre un contrato de venta, así que el capítulo IX del Convenio también se excluye. El capítulo XI del Convenio tampoco se aplica a las ventas porque es sustituido por el art. III del Protocolo. En ningún caso el art. 43 del Convenio referente a la jurisdicción en el caso de las medidas provisionales es susceptible de aplicarse a las ventas, porque el artículo 13 (capítulo III de Convenio) referente a medidas provisionales no se aplica a las ventas. Y por último, el art. 60 sobre garantías preexistentes no es de aplicación a las ventas porque es innecesario. 
aplicación a las ventas son: definiciones, ámbito de aplicación personal, interpretación y ley aplicable, Registro Internacional, efectos de la insolvencia, declaraciones de los arts. 39 y 40, jurisdicción, salvo la referente a las medidas provisionales, relación con otros Convenios y disposiciones finales, salvo las del artículo 60 del Convenio ${ }^{73}$.

En consecuencia, cualquier referencia que se haga al acreedor, por extraño que parezca, se entenderá realizada a comprador y al deudor, se le asimilará con el vendedor ${ }^{74}$. Así, si el ámbito de aplicación personal es que el deudor esté domiciliado en un Estado contratante en virtud del art. 3 del Convenio; en el caso de las ventas, será de aplicación el Convenio y su Protocolo cuando sea el vendedor el que está domiciliado en un Estado contratante. De la misma manera que es el comprador el legitimado para proceder a la inscripción, puesto que en el caso de los contratos de garantía es el acreedor.

Una venta lleva implícita una transferencia de propiedad, de manera que un simple acuerdo para vender en el que la propiedad no ha pasado al comprador no puede registrarse como una venta, pero sí que puede registrarse como una venta futura o, si contiene una expresa reserva de dominio, como un contrato de compraventa con reserva de dominio ${ }^{75}$. Por ejemplo, en un contrato de arrendamiento con opción de compra, el arrendatario podría ser un comprador futuro. Por lo tanto, el arrendador puede registrar su derecho como arrendador, mientras que el arrendatario puede registrar su derecho separado como comprador futuro. El ejercicio de la opción de compra extingue el derecho del arrendador, mientras que cancela la inscripción del arrendatario referente a la opción de compra y pasa a estar registrado como comprador. Pero esto se podría evitar si el arrendatario hubiese registrado su derecho como una compra futura para evitar ser desplazado por otro comprador o comprador futuro al cual el arrendador vende o acuerda vender el objeto, y se registró primero. Si la opción de compra no se ejerce o se extingue por la terminación del contrato de arrendamiento por incumplimiento, el arrendador procederá a la cancelación de la inscripción como compra futura.

Para que sea considerada una transacción como una venta a efectos del Convenio, es necesario que se realice a través de un contrato en el que se produce la venta completa del objeto aeronáutico, por la cual la garantía del vendedor pasa inmediatamente al comprador. Por lo tanto, una factura de venta ("bill of sale" en inglés) puede ser considerada una garantía inscribible, pero un contrato de compraventa en el que se establece la entrega de la factura de venta no sería considerado como tal, en todo caso el contrato de compraventa puede llegar a ser una venta futura registrable.

Por último, en relación con las ventas, dado que en la práctica han adquirido gran relevancia los programas de fractional aircraft ownership se van a abordar los fractional interests. Una garantía adquirida sobre un objeto aeronáutico mediante un contrato de venta, puede corresponder a una sóla parte o a múltiples partes. Pero también es común que se adquiera la propiedad entre varios copropietarios en la que se especifican los porcentajes o fracciones de la garantía que a cada uno le correspondería, denominados fractional interests. El Convenio no aborda expresamente los fractional interests, pero nada obsta a que sean tratados como una garantía separada. Cada compra de un fractional interest sobre un objeto aeronáutico se puede registrar de manera separada, así si un objeto aeronáutico se vende en $40 \%$, un $20 \%$ y un $30 \%$ a distintas compañías, las tres ventas son registrables en el Registro Internacional ${ }^{16}$. De la misma manera que la compra de un fractional interest puede ser financiado por un acreedor diferente, que también garantiza o asegura ese particular fractional interest, por lo que también cada uno constituye una garantía internacional y puede ser registrado también. En los casos de fractional interest que, como se ha visto, se constituyen sobre partes diferentes del objeto aeronáutico, compiten al mismo nivel dentro de las reglas de prioridad. Sin embargo, existen dos excepciones: 1) cuando la misma

73 También existen disposiciones del Protocolo que no se aplican a las ventas y que están en relación con las que no se aplican del Convenio y que son los arts. IX a XIII (modificaciones de las medidas en caso de incumplimiento y de insolvencia), el artículo XV (modificación de las medidas relativas a las cesiones) y el art. XVI (disposiciones relativas al deudor, salvo en relación a la capacidad del deudor como comprador) (R. Goode, Official Commentary. Revised Edition. Convention on International Interests in Mobile Equipment and Protocol Thereto on Matters Specific to Aircraft Equipment, Unidroit, Roma, 2008, p. 309).

74 R. Goode, Official Commentary. Revised Edition. Convention on International Interests in Mobile Equipment and Protocol Thereto on Matters Specific to Aircraft Equipment, Unidroit, Roma, 2008, p. 310.

75 Ibidem, pp. 310-311.

76 Idem, p. 31. 
parte de un mismo fractional interest, es vendida a compradores bajo diferentes contratos de venta o son garantizados por diferentes acreedores; 2) cuando los vendedores juntos que venden o los deudores que garantizan mediante los fractional interest, exceden el 100\% del valor del objeto. En estos casos, la prioridad es determinada por orden de registro.

17. Se debe añadir que también se encuentran dentro de esta categoría de garantías internacionales las que podríamos denominar como sub-garantías (sub-interests en la versión inglesa), que son garantías internacionales en favor de una persona que a su vez ha sido garantizada por una garantía principal. Ejemplos de subgarantías son las garantías internacionales que surgen en favor de un comprador condicional que ha alquilado el bien adquirido o en favor del arrendatario que ha concedido un sub-leasing ${ }^{77}$.

18. Las garantías internacionales futuras. Son aquellas garantías internacionales que se pretenden crear o constituir en el futuro sobre un objeto aeronáutico ya existente e identificable (art. 1.y). Dichas garantías se pueden registrar como tales, aunque no se llegue a producir el hecho del que deriva su creación, como en el caso de que las partes estén negociando las condiciones del contrato o que el deudor todavía no haya adquirido un derecho sobre el objeto aeronáutico que va a ser gravado ${ }^{78}$. Sin embargo, su eficacia está supeditada a que se convierta en una garantía internacional, cumpliendo, claro está, los requisitos del art. 7 del Convenio. En el caso de que finalmente se constituya la garantía internacional, ésta gozará de prelación desde el momento de la inscripción de la garantía internacional futura.

19. Las garantías nacionales. Son aquellas garantías inscritas bajo un sistema de registro nacional, creadas en virtud de una transacción interna, es decir, en un supuesto en el que todas las conexiones se encuentren en un mismo Estado, con respecto a las cuales el Estado contratante ha hecho una declaración conforme al art. 50 del Convenio, con el objetivo de excluir la aplicación del mismo a dichas transacciones internas ${ }^{79}$. Sin embargo, el efecto de esta exclusión es limitado. En primer lugar, estas garantías nacionales pueden tener eficacia internacional si se inscriben en el Registro Internacional como un aviso de garantía nacional, asegurándose la prioridad de la misma forma en que se beneficiaría una garantía internacional ${ }^{80}$. En segundo lugar, a dichas garantías nacionales les siguen siendo de aplicación las reglas de prioridad del Convenio, así como diversas disposiciones del Convenio ${ }^{81}$.

Tan sólo cinco Estados contratantes de los que han ratificado el Convenio y su Protocolo Aeronáutico, han hecho la declaración del art. 50, para que no se apliquen las normas del Convenio a las garantías nacionales, entre los que se debe mencionar China por su importancia en la industria aeronáutica $^{82}$. En el caso de España, como no hizo la declaración del art. 50 en el momento de su adhesión al Convenio no tiene que hacer avisos de garantías nacionales, para que ganen prioridad internacional.

20. Los derechos o garantías no contractuales no inscritos. El Convenio permite que mediante la declaración contemplada en su art. 39.1.a), los Estados contratantes designen aquellos derechos o garantías no contractuales que, conforme a su ordenamiento nacional, gozarían de una prioridad equivalente a

77 Idem, p. 24.

78 Idem, p. 24.

${ }^{79} \mathrm{El}$ art. 1.n del Convenio define transacción interna: “(...) cuando el lugar en el que están concentrados los intereses de todas las partes en esa transacción está situado, y el objeto pertinente se encuentra (como se especifica en el Protocolo), en el mismo Estado contratante en el momento en el que se celabra el contrato y cuando la garantía creada por la transacción ha sido inscrita en un registro nacional en ese Estado contratante que ha formulado una declaración en virtud del párrafo 1 del art. 50 (...)”. Si el Estado no hace la declaración conforme al art. 50 del Convenio, tales garantías serán registradas como garantías internacionales.

80 R. Goode, Official Commentary. Revised Edition. Convention on International Interests in Mobile Equipment and Protocol Thereto on Matters Specific to Aircraft Equipment, Unidroit, Roma, 2008, p. 24.

${ }^{81}$ Entre las disposiciones que le siguen siendo de aplicación a pesar de que el Estado contratante haga la declaración en virtud del art. 50 del Convenio, son las de los arts. 8.4, 9.1 y 16, y las del Capítulo V.

${ }^{82}$ La declaración realizada por China en este sentido es la siguiente: "4. Declaration under Article 50(1) of the Convention: The Convention shall not apply to a transaction which is an internal transaction in relation to the PRC." (disponible en línea en http://www.unidroit.org/status-2001 capetown?id=463 (consultado el día 16 de noviembre de 2016)). 
las garantías internacionales ${ }^{83}$. De tal manera, que gozarían de prioridad sobre garantías internacionales inscritas, en el marco de procedimientos de insolvencia si así se establece, o incluso sobre garantías internacionales inscritas antes de la ratificación del Protocolo aeronáutico (arts. 39.1.a) y 39.4). Serían ejemplos de estos derechos o garantías no contractuales no inscritos susceptibles de protección: los créditos laborales, los créditos fiscales, premios por salvamento o derechos de retención que permitan al poseedor conservar la cosa hasta que le sean satisfechos por el deudor determinados créditos relacionados con ellos.

También un Estado puede declarar tal y como señala el art. 39.1.b) que: “(...) ninguna de las disposiciones del presente Convenio afectará al derecho de un Estado o de una entidad estatal, de una organización intergubernamental o de otro proveedor de servicios públicos a embargar o detener un objeto en virtud de las leyes de dicho Estado por el pago de las cantidades adeudadas a esa entidad, organización o proveedor en relación directa con esos servicios respecto de ese objeto o de otro objeto". A efectos de esta disposición es totalmente irrelevante si el derecho de embargo o detención está previsto por la ley o por el contrato. La calificación como contractual o no contractual deberá realizarse conforme al ordenamiento del Estado que haga la declaración.

La mayoría de los Estados, entre los que está España han realizado las declaraciones conforme a los arts. 39.1.a) y 39.1.b $)^{84}$. Así que España en su reciente adhesión al Protocolo Aeronáutico, ha realizado la siguiente declaración por lo que respecta al art. 39.1.a): “(...) El Reino de España declara que todas las categorías de derechos o garantías no contractuales que conforme a la ley española tienen y tendrán prioridad en el futuro sobre una garantía relativa a un objeto que sea equivalente a la del titular de una garantía internacional inscrita, tendrán prioridad en igual medida sobre una garantía internacional inscrita, tanto dentro como fuera de un procedimiento de insolvencia, y tanto si fue registrada antes o después de la adhesión del Reino de España" ${ }^{" 55}$. En el caso de España, se corresponden básicamente con los contemplados: en el art. 133 de la Ley española de Navegación Aérea de 1960, que recoge los créditos privilegiados y en el art. 41 de la Ley de Hipoteca Mobiliaria y Prenda Sin Desplazamiento de 1954, que protege las remuneraciones por salvamento ${ }^{86}$.

Por lo que respecta a la declaración realizada por España en virtud del art, 39.1.b), es tan genérica como la arriba señalada: "(...) el Reino de España declara que ninguna de las disposiciones del presente Convenio afectará su derecho o el de una entidad pública, organización internacional de la

83 R. Goode, Official Commentary. Revised Edition. Convention on International Interests in Mobile Equipment and Protocol Thereto on Matters Specific to Aircraft Equipment, Unidroit, Roma, 2008, pp. 24-25.

${ }^{84}$ Se puede ver la diferencia entre las declaraciones realizadas en relación con dicho artículo. En primer lugar, la declaración realizada por Estados Unidos más general: “(1) Pursuant to Article 39 of the Convention - (A) all categories of non-consensual rights or interests which under United States law have and will in the future have priority over an interest in an object equivalent to that of the holder of a registered international interest shall to that extent have priority over a registered international interest, whether in or outside insolvency proceedings; and (B) nothing in the Convention shall affect the right of the United States or that of any entity thereof, any intergovernmental organization in which the United States is a member State, or other private provider of public services in the United States to arrest or detain an aircraft object under United States law for payment of amounts owed to any such entity, organization, or provider directly relating to the services provided by it in respect of that object or another object." (disponible en línea en http://www.unidroit.org/status-2001 capetown?id=496 (consultado el 16 de noviembre de 2016). En segundo lugar, la declaración realizada por China, en la que se detallan los derechos o garantías no cntractuales que gozan de prioridad: "1. Declaration under Article 39(1)(a) of the Convention: All non-consensual rights or interestswhich have priority over secured creditors under the law of the PRC shall have priority without registration over registered international interests, including but not limited to: claim for bankruptcy expenses and community debts, employee's wages, taxes arising prior to the mortgage, pledge or lien of the civil aircraft, claim for remuneration for rescuing the civil aircraft, claim for necessary expenses incurred for the custody and maintenance thereof of the civil aircraft, etc. Declaration under Article 39(1)(b) of the Convention: Nothing in this Convention shall affect the right of a State or State entity, intergovernmental organization or other provider of public services to arrest or detain an object under the laws of the PRC for payment of amounts owed to such entity, organization or provider directly relating to those services in respect of that object or another object.Declaration under Article 39(4) of the Convention: A right or interest of a category covered by the declaration made under Article 39(1)(a) shall have priority over an international interest registered prior to the date of ratification of the Protocol." (disponible en línea en http://www.unidroit.org/status-2001 capetown?id=463 (consultado el 16 de noviembre de 2016)).

${ }^{85}$ Instrumento de adhesión al Protocolo sobre cuestiones específicas de los elementos de equipo aeronáutico, del Convenio relativo a garantías internacionales sobre elementos de equipo móvil, hecho en Ciudad del Cabo el 16 de noviembre de 2001, BOE núm. 27, 1 febrero 2016.

86 Art. 133 Ley 48/1960, de 21 de julio, sobre Navegación Aérea, BOE núm. 313, 31 diciembre 1969; art. 41 de la Ley de diciembre de 1954 sobre Hipoteca Mobiliaria y prenda sin desplazamiento de posesión, BOE núm. 352, 18 diciembre 1954. 
que el Reino de España sea parte u otro proveedor privado de servicios públicos en el Reino de España a embargar o detener un objeto en virtud de las leyes españolas para el pago de las cantidades adeudadas al Reino de España o a cualquiera de las mencionadas entidades, organizaciones o proveedores que tengan una relación directa con los servicios prestados respecto de ese u otro objeto" ${ }^{87}$. Se trata en definitiva de garantizar el derecho de los prestadores de servicios públicos, con independencia de que se trate de entidades estatales, privadas o incluso intergubernamentales, como por ejemplo Eurocontrol, a retener un bien para lograr el pago de las deudas por los servicios que hubieran prestado.

21. Los derechos o garantías no contractuales susceptibles de inscripción. Se diferencian de la categoría anterior porque su prioridad depende de su inscripción en el Registro Internaciona ${ }^{88}$. Como la categoría anterior, son derechos y garantías no contractuales porque no nacen del acuerdo entre las partes, que es precisamente uno de los requisitos para la constitución de las garantías internacionales, y serían, por ejemplo, los embargos o los privilegios legales. Pues bien, el Convenio permite a los Estados que hagan una declaración de conformidad con el art. 40, estableciendo las garantías o derechos de naturaleza no contractual y creados de acuerdo con su ley nacional, que podrán inscribirse en el Registro Internacional como si fueran garantías internacionales y ser tratados como tales. Si tales derechos o garantías no contractuales no se inscriben, no ganarán la prioridad que le otorga el Convenio y tendrán un efecto muy limitado bajo el Convenio. De hecho, únicamente se aplicaría el Convenio al hecho de que el titular del derecho o garantía no contractual inscribible pero que no se ha inscrito, sea tratado como persona interesada a los efectos del ejercicio de medidas en caso de incumplimiento. Cuestión esta última, relevante por ejemplo, porque deberá recibir un aviso por escrito y con una antelación razonable del acreedor garantizado que decide vender o arrendar el objeto aeronáutico ante el incumplimiento del deudor, posibilidad que se contempla en el art. 8.4 del Convenio ${ }^{89}$.

Como en el caso de la anterior categoría, un buen número de Estados han realizado la declaración contemplada en el art. 40 del Convenio ${ }^{90}$. De hecho, España ha señalado que los derechos o garantías no contractuales que deben gozar del prioridad internacional son: " $a$ ) derechos de una persona que haya obtenido una orden judicial que autorice el embargo de un objeto aeronáutico para el cumplimiento total o parcial de la resolución de un Tribunal, y b) gravámenes u otros derechos de una entidad estatal en relación con impuestos u otros tributos no abonados" ${ }^{\prime 1}$. Estos pueden inscribirse

\footnotetext{
87 Instrumento de adhesión al Protocolo sobre cuestiones específicas de los elementos de equipo aeronáutico, del Convenio relativo a garantías internacionales sobre elementos de equipo móvil, hecho en Ciudad del Cabo el 16 de noviembre de 2001, BOE núm. 27, 1 febrero 2016.

88 R. Goode, Official Commentary. Revised Edition. Convention on International Interests in Mobile Equipment and Protocol Thereto on Matters Specific to Aircraft Equipment, Unidroit, Roma, 2008, p. 25.

89 Ibidem, p. 25.

90 Existen también diferencias en las declaraciones relativas al art. 40 del Convenio. En primer lugar, la declaración realizada por la India es la siguiente: “(iii) Form No. 6 (Declaration under Article 40): The following categories of non-consensual right or interest shall be registrable under the Convention as regards any category of aircraft object as if the right or interest were an international interest and shall be regulated accordingly, namely:-(a) liens in favour of airline employees for unpaid wages arising prior to the time of a declared default by that airline under a contract to finance or lease an aircraft object; (b) liens or other rights of an authority of India relating to taxes or other unpaid charges arising from or related to the use of an aircraft object and owed by the owner or operator of that aircraft object, arising prior to the time of a declared default by that owner or operator under a contract to finance or lease that aircraft object; and (c) rights of a person obtaining a court order permitting attachment of an aircraft object in partial or full satisfaction of a legal judgment." (disponible en línea en http://www.unidroit.org/status-2001 capetown?id=468 (consultado el 29 de octubre de 2015)). Mientras que la declaración realizada por Emiratos Árabes es: "(iii) Form No. 6 (Declaration under Article 40) The United Arab Emirates declares that the following categories of non-consensual right or interest: (a) rights of a person obtaining a court order permitting attachment of an aircraft object in partial or full satisfaction of a legal judgement; (b) liens in favour of workers for unpaid wages arising prior to the time of a declared default under a contract to finance or lease the subject object; (c) liens or other rights of a state entity relating to taxes or other unpaid charges arising; (d) all other nonconsensual rights or interests which under the law of the United Arab Emirates could have priority over the rights of secured creditors - shall be registrable under the Convention as regards any category of object as if the right or interest were an international interest and shall be regulated accordingly." (disponible en línea en http://www.unidroit.org/status-2001 capetown?id=494 (consultado el 16 de noviembre de 2016)).

${ }^{91}$ Instrumento de adhesión al Protocolo sobre cuestiones específicas de los elementos de equipo aeronáutico, del Convenio relativo a garantías internacionales sobre elementos de equipo móvil, hecho en Ciudad del Cabo el 16 de noviembre de 2001, BOE núm. 27, 1 febrero 2016.
} 
en virtud del Convenio como si se tratara de derechos o garantías internacionales y serán regulados como tales.

22. Los derechos accesorios, se definen como todos los derechos al pago o a otra forma de ejecución por un deudor en virtud de un contrato y que estén garantizados por el objeto o relacionados con el mismo (art. 1.c). Por lo tanto, los derechos personales de crédito sin garantía real están fuera del ámbito de aplicación del Convenio, salvo la preservación de la eficacia contractual de derechos legales y contractuales de embargo o detención del objeto aeronáutico, reconocidos en virtud de las leyes del Estado, por las cantidades adeudadas al prestador de servicios públicos, siempre que el Estado contratante haga una declaración en este sentido conforme al art. 39.1.b) del Convenio ${ }^{92}$. En cualquier caso, la importancia de estos derechos accesorios se limita casi de forma exclusiva a los supuestos en los que son objeto de cesión.

Los derechos accesorios no son inscribibles, pero están en relación con la cesión de derechos, que sí que lo son.

23. Los derechos o garantías preexistentes. El Convenio no es de aplicación a tales derechos o garantías preexistentes, salvo que el Estado contratante declare otra cosa distinta en virtud del art. 60.3 del Convenio ${ }^{93}$. Por lo tanto, si no se realiza tal declaración, los derechos o garantías preexistentes de un Estado contratante conservarán la prioridad que tuviesen según la ley aplicable antes de la fecha en que tenga efecto el Convenio, que es -con relación a un deudor-, la fecha posterior de entre las dos siguientes: la de entrada en vigor del Convenio y la de incorporación como Estado contratante del Estado donde el deudor está situado (art. 60.1 y 60.2.a)).

España por su parte no ha hecho la declaración en virtud del art. 60.3 del Convenio, por lo que el Convenio no se aplicará a estos derechos. En este sentido, a excepción de Canadá y México, ningún Estado contratante ha hecho la declaración con respecto a garantías preexistentes.

\section{La "implementación" en España del Registro Internacional}

24. En el nuevo Real Decreto sobre matriculación de aeronaves civiles del año 2015, se añadió la disposición adicional sexta con el objeto de intentar articular la relación entre el Registro Internacional y los dos registros que existen en España, donde es posible la inscripción de las aeronaves o de los objetos aeronáuticos, como son las célulasde las aeronaves, los motores de las aeronaves y los helicópteros, y que son el Registro de Bienes Muebles y el Registro de Matrícula de Aeronaves Civiles ${ }^{94}$. Para adelantar ya uno de los problemas que se plantean es que en el Registro Internacional se inscriben garantías en relación con objetos aeronáuticos, mientras que cuando se trata de la inscripción en el Registro de Bienes Muebles y en el de Matrícula, se está haciendo referencia a aeronaves, con los motores instalados. Lo cual no quiere decir que en el Registro de Bienes Muebles no se puedan inscribir los derechos de manera separada sobre los motores. Sin embargo, no se pueden inscribir en el Registro de Matrícula, pues los motores no gozan de matrícula, tal y como señala el Convenio de Chicago de 1944.

Por esta razón, se van a explicar los dos registros españoles, pues son los que van a estar en relación con el Registro Internacional, con el objetivo de que el "Sistema de Ciudad del Cabo" sea implementado de manera efectiva en España.

92 R. Goode, Official Commentary. Revised Edition. Convention on International Interests in Mobile Equipment and Protocol Thereto on Matters Specific to Aircraft Equipment, Unidroit, Roma, 2008, p. 26.

93 Sobre las importantes normas de Derecho transitorio contempladas en el art. 60.3 del Convenio vid. R. GoodE, Official Commentary. Revised Edition. Convention on International Interests in Mobile Equipment and Protocol Thereto on Matters Specific to Aircraft Equipment, Unidroit, Roma, 2008, pp. 95-96.

$94 \mathrm{Si}$ bien en otros países existe un único registro donde se inscribe la matrícula de la aeronave, así como los derechos y gravámenes, este es el sistema predominante en Iberoamérica, en países como Argentina, Brasil, Colombia, Costa Rica, Cuba, Chile, Ecuador, Méjico, Paraguay, Uruguay o Venezuela, aunque también lo han adoptado algunos países de Europa como Francia, Italia, Portugal o Suecia. Mientras que en otros países existe un doble sistema registral como en España siendo este el caso de algunos países de Iberoamérica, como Bolivia, Honduras, Nicaragua, Panamá, República Dominicana y El Salvador. Este sistema de doble registro dificulta la "implantación" del Registro Internacional en España. 


\section{El Registro de Bienes Muebles como punto de acceso autorizante}

25. Además de las declaraciones que ha realizado España en otras materias, se va a citar de manera literal, la realizada con respecto al Registro Internacional de conformidad con el art. XIX.1 del Protocolo aeronáutico: "El Registro de Bienes Muebles será el punto de acceso que autorizará la transmisión al Registro Internacional de la información necesaria para la inscripción con relación a las células de aeronaves o helicópteros matriculados en el Reino de España o en proceso de matriculación, y que podrá autorizar la transmisión de la mencionada información a dicho Registro con relación a los motores de aeronaves".

España ha optado pues por un punto de acceso autorizante, que será obligatorio para las células de aeronaves y los helicópteros, mientras que será opcional en el caso de los motores de aeronaves, que podrán inscribirse o bien a través del Registro de Bienes Muebles o directamente a través del Registro Internacional ${ }^{95}$.

26. El Registro de Bienes Muebles es actualmente donde se registran las titularidades y gravámenes que existen sobre las aeronaves, aunque en un primer momento tales inscripciones se registraban en el Registro Mercanti1 ${ }^{96}$.

El art. 179 del Reglamento del Registro Mercantil de 1956 es el que establece que se inscribirán en dicho Registro Mercantil las aeronaves de nacionalidad española y de propiedad privada que se destinen o puedan destinarse a usos industriales o mercantiles ${ }^{97}$. Sin embargo, la disposición adicional única del Real Decreto 1828/1999, por el que se aprueba el Reglamento del Registro de Condiciones Generales de la Contratación señalaba que las aeronaves debían inscribirse en la sección primera del Registro de Bienes Muebles ${ }^{98}$. Con lo cual se suscitó la cuestión de si las aeronaves debían seguir siendo objeto de incripción en el Registro Mercantil. La respuesta a esta pregunta fue resuelta a través de la Resolución de la Dirección General de los Registros y del Notariado de 11 de abril de 2000, sobre determinadas cuestiones derivadas de la creación del Registro de Bienes Muebles, que señaló que: "En la sección de buques y aeronaves (sección primera) del nuevo Registro de Bienes Muebles se deben practicar todas las inscripciones de actos y contratos relativas a embarcaciones y aeronaves, con independencia (con relación a los buques) de la lista en la que estén inscritas en el Registro administrativo correspondiente. Cada uno de los actos, contratos y gravámenes (compraventas, al contado o a plazos, arrendamientos, hipoteca naval o mobiliaria, anotación de embargo o demanda, ejecución forzosa, etcétera) que se rea-

95 Art.12.2 Normas del Registro Internacional (R. Goode, Official Commentary. Revised Edition. Convention on International Interests in Mobile Equipment and Protocol Thereto on Matters Specific to Aircraft Equipment, Unidroit, Roma, 2008, p. 436).

96 Cuando se crea el Registro de Bienes Muebles en 1999 se establece: "El Registro de Bienes Muebles es un Registro de titularidades y gravámenes sobre bienes muebles, así como de condiciones generales de la contratación. Dentro de cada una de las secciones que lo integran se aplicará la normativa especifica reguladora de los actos o derechos inscribibles que afecten a los bienes, o a la correpondiente a las condiciones generales de la contratación" (Apartado 2 de la disposición adicional única RD 1828/1999, de 3 de diciembre, por el que se aprueba el Reglamento del Registro de Condiciones Generales de la Contratación, BOE núm. 306, 23 diciembre 1999).

97 Aunque el Reglamento del Registro Mercantil vigente es el de 1996, en lo que respecta a la inscripción de buques y aeronaves sigue estando en vigor el Reglamento del Registro Mercantil de 1956, aprobado por el Decreto de 14 de diciembre de 1956 (BOE núm. 66, 7 marzo 1957; corrección de errores en BOE núm. 73, 14 marzo 1957). Vid. Disp. Trans. 13a . del RD 1784/1996, de 19 de julio, por el que se aprueba el Reglamento del Registro Mercantil, BOE núm. 184, 31 julio 1996. Por lo tanto, de dicho Reglamento del Registro Mercantil de 1956 está en vigor en materia de inscripción de aeronaves, el Título VI.

98 Apartado 1 de la disposición adicional única RD 1828/1999, de 3 de diciembre, por el que se aprueba el Reglamento del Registro de Condiciones Generales de la Contratación, BOE núm. 306, 23 diciembre 1999. El cambio de la inscripción de las titularidades y gravámenes de las aeronaves, desde el Registro Mercantil al Registro de Bienes Muebles se produce como consecuencia de la disposición final segunda de la Ley 19/1989, de 25 de julio, de reforma parcial y adaptación de la legislación mercantil a las Directivas de la comunidad Económica Europea (CEE) en materia de Sociedades (BOE núm. 178, 27 julio 1989), que autorizó al Gobierno para la regulación del Registro de Bienes Muebles, en el cual se unificarían los actuales Registros de Hipoteca Mobiliaria y Prenda sin desplazamiento y los de Buques y Aeronaves. De la misma manera, que la disposición adicional tercera de la Ley 28/1998, de 13 de julio, de Venta a Plazos de Bienes Muebles (BOE núm. 167, 14 julio 1998), establece que el Registro de Venta a Plazos de Bienes Muebles se integraría en el Registro de Bienes Muebles, a cargo de los registradores de la propiedad y mercantiles, según dispusiera su Reglamento. De momento, no está en vigor el Reglamento del Registro de Bienes Muebles. 
licen sobre tales bienes serán calificados y en su caso inscritos o anotados preventivamente dentro de dicha Sección por el Registrador de Bienes Muebles" "99. Por lo tanto, queda suficientemente claro que las titularidades y gravámenes de las aeronaves se inscriben en el Registro de Bienes Muebles; pero habría que determinar qué Registrador será el competente para llevar a cabo las inscripciones.

Se puede deducir de lo anterior que el Libro de Aeronaves sólo existía en el Registro Mercantil territorial de Madrid desde 1956 ${ }^{100}$. Y fue el mencionado Real Decreto 1828/1999 el que en su disposición transitoria única el que estableció que hasta que no se modificase la demarcación registral correspondiente al Registro de Bienes Muebles, las secciones que lo formaran seguirían a cargo del registrador de la propiedad y mercantil que en el momento de la entrada en vigor del Real Decreto tuviese la competencia ${ }^{101}$. Por lo tanto, la competencia se atribuye al Registro Mercantil Provincial de Madrid por ser la única provincia donde existe Registro de Matrícula de aeronaves, de manera que queda en suspenso el criterio sostenido en el apartado 4 de la disposición transitoria de la Ordenanza de 19 de julio de 1999 para el Registro de Venta a Plazos de Bienes Muebles, que atribuye al Registro Central de la Propiedad Mobiliaria la competencia sobre la inscripción de aeronaves ${ }^{102}$. Esto por lo que respecta a la inscripción del dominio y demás actos y contratos de transcendencia real relativos a la aeronave, según el art. 177 del Reglamento del Registro Mercantil de $1956^{103}$.

Sin embargo, aunque los arts. 177 a 190 del Reglamento del Registro Mercantil de 1956 no prevén expresamente la inscripción de los contratos de venta a plazos y arrendamientos sobre aeronaves, la Ley 28/1998 de Venta a Plazos de Bienes Muebles sí que contempla la inscripción de dichos contratos ya que las aeronaves son bienes corporales no consumibles e identificables ${ }^{104}$. Y es la Ordenanza de 19 de julio de 1999 antes citada, la que señala que será competente para la inscripción de los contratos de venta a plazos y de arrendamientos sobre aeronaves, el Registro correspondiente al domicilio del comprador o arrendatario, o siendo varios, el de cualquiera de ellos ${ }^{105}$. Por lo tanto, en principio los Registradores Mercantiles Provinciales a cargo del Registro de Bienes Muebles serán también competentes para inscribir en su sección primera (buques y aeronaves), los contratos de venta a plazos y de arrendamiento financiero de aeronaves, siendo el domicilio del comprador o del arrendatario el criterio determinante de la competencia ${ }^{106}$.

Pero se añade en la Resolución de la DGRN de 29 de enero de 2001 que una vez inmatriculada la aeronave en virtud de uno de los criterios anteriores, el Registro donde se hubiera inmatriculado será competente para la inscripción de los demás actos y contratos sobre la aeronave, dado el principio de tracto sucesivo que caracteriza a los Registros de bienes ${ }^{107}$.

99 Resol. DGRN de 11 de abril de 2000, Anuario de la Dirección General de los Registros y del Notariado, vol. I, 2000, pp. 2129-2131.

100 Dicho Libro de Aeronaves estaba en el Registro Mercantil de Madrid, porque es donde se encontraba la sede del Registro de Matrícula. Pues el art. 177 del Reglamento del Registro Mercantil de 1956, aprobado por el Decreto de 14 de diciembre de 1956 (BOE núm. 66, 7 marzo 1957; corrección de errores en BOE núm. 73, 14 marzo 1959) establecía: "En el Registro Mercantil de la provincia donde hubiere matrícula de aeronaves se abrirá una sección especial para la inscripción del dominio y demás actos y contratos de transcendencia real relativos a las mismas".

101 Disposición transitoria única RD 1828/1999, de 3 de diciembre, por el que se aprueba el Reglamento del Registro de Condiciones Generales de la Contratación, BOE núm. 306, 23 diciembre 1999. También lo establece la Resol. DGRN de 11 de abril de 2000, Anuario de la Dirección General de los Registros y del Notariado, vol. I, 2000, pp. 2129-2131.

Así como la Resol. DGRN de 29 de enero de 2001, Anuario de la Dirección General de los Registros y del Notariado, vol. I, 2001, pp. 2183-2188.

102 Apartado 4 disposición transitoria Orden de 19 de julio de 1999 por la que se aprueba la Ordenanza para el Registro de Venta a Plazos de Bienes Muebles, BOE núm. 172, 20 julio 1999; Resol. DGRN de 29 de enero de 2001, Anuario de la Dirección General de los Registros y del Notariado, vol. I, 2001, pp. 2183-2188.

103 Resol. DGRN de 29 de enero de 2001, Anuario de la Dirección General de los Registros y del Notariado, vol. I, 2001, pp. 2183-2188.

104 Disposición adicional primera Ley 28/1998, de 13 de julio, de Venta a Plazos de Bienes Muebles, BOE núm. 167, 14 julio 1998.

105 Art. 9 Orden de 19 de julio de 1999 por la que se aprueba la Ordenanza para el Registro de Venta a Plazos de Bienes Muebles, BOE núm. 172, 20 julio 1999; Resol. DGRN de 29 de enero de 2001, Anuario de la Dirección General de los Registros y del Notariado, vol. I, 2001, pp. 2183-2188.

106 Se señala en principio porque como se verá más adelante en la práctica esto no es así.

107 Resol. DGRN de 29 de enero de 2001, Anuario de la Dirección General de los Registros y del Notariado, vol. I, 2001, pp. 2183-2188. 
27. Se debe recordar que la primera inscripción de la aeronave se debe realizar en el Registro de Matrícula, para la obtención de la matrícula, ya sea adquirida en virtud de un título de propiedad, de un contrato de arrendamiento o cualquier otro título traslativo de posesión o uso de la aeronave ${ }^{108}$. Posteriormente se inscribirán cuando proceda en el Registro de Bienes Muebles, de conformidad con su normativa específica ${ }^{109}$. Sin embargo, el art. 180 del Reglamento del Registro Mercantil de 1956 señala que la primera inscripción de la aeronave ha de ser obligatoriamente la del dominio ${ }^{110}$. Esto provoca que si la aeronave se inscribe en el Registro de Matrícula en virtud de un contrato de arrendamiento sobre la misma, dicho contrato no va a poder ser inscrito en el Registro de Bienes Muebles por el Registrador Mercantil de Madrid. Pero además, si la aeronave ya consta en el Registro de Bienes Muebles de Madrid por un título de propiedad, los contratos de arrendamiento posteriores no van a poder ser inscritos por los Registradores Mercantiles de otras provincias, como por ejemplo el de Sevilla -debido a que el domicilio del arrendatario se encuentre en ese lugar- porque como consecuencia del principio de tracto sucesivo, cualquier arrendamiento posterior deberá inmatricularse en el Registro de Bienes Muebles de la provincia donde se hubiere inmatriculado en primer lugar, que es el Registro de Bienes Muebles de Madrid, a cargo de los Registradores Mercantiles de Madrid. En definitiva, el Registro de Bienes Muebles de Madrid es el único Registro competente para la inscripción de las aeronaves, porque es en Madrid donde se ubica el Registro de Matrícula de Aeronaves Civiles, a pesar de los argumentos esgrimidos por la Resolución de la DGRN de 29 de enero de 2001 otorgando también la competencia a los Registros de Bienes Muebles de otras provincias ${ }^{111}$.

28. Por lo que respecta a los motores, la Resolución de la DGRN del 29 de enero de 2001 establecía que eran inscribibles en el Registro de Bienes Muebles, tanto los motores de aeronaves como las piezas de repuesto, siempre que reúniesen los caracteres de bienes identificables, en virtud del art. 6.2 de la Ordenanza de 19 de julio de 1999, es decir: "todos aquéllos en los que conste impresa la marca, modelo en su caso, y número de serie o fabricación de forma indeleble o inseparable en una o varias de sus partes fundamentales o que tengan alguna característica distintiva que excluya su confusión con otros bienes" "12. Además, como se trataba de elementos accesorios identificables, en la misma Ordenanza se señala que se incribirán en la Sección a la que pertenezca el elemento principal, por lo tanto deberán registrarse en la sección primera, que es donde se inscriben las aeronaves. Así lo confirma la Resolución de la DGRN de 29 de enero de 2001, en la que se afirma que la inscripción de las piezas de repuesto y de los motores se practicará en la sección primera, abriendo folio separado a cada bien ${ }^{113}$.

108 Art. 10.2 RD 384/2015, de 22 de mayo, por el que se aprueba el Reglamento de matriculación de aeronaves civiles, BOE núm. 144, 17 junio 2015.

109 Art. 10.1 RD 384/2015, de 22 de mayo, por el que se aprueba el Reglamento de matriculación de aeronaves civiles, BOE núm. 144, 17 junio 2015.

110 Art. 180 Reglamento del Registro Mercantil de 1956, aprobado por el Decreto de 14 de diciembre de 1956, BOE núm. 66, 7 marzo 1957; corrección de errores en BOE núm. 73, 14 marzo 1957.

111 Vid. página del Registro de Bienes Muebles de Madrid, diponible en línea en https://www.rmercantilmadrid.com/rmm/ DocumentosBienesMuebles.aspx (consultada el 16 de noviembre de 2016).

112 Art. 6.2 Orden de 19 de julio de 1999 por la que se aprueba la Ordenanza para el Registro de Venta a Plazos de Bienes Muebles, BOE núm. 172, 20 julio 1999. Esta misma definición sobre bien identificable es la que señala el art. 1.2 de la Ley 28/1998, de 13 de julio, de Venta a Plazos de Bienes Muebles (BOE núm. 167, 14 julio 1998).

113 Sin embargo, algunos autores afirmaban que en la práctica los contratos que tengan por objeto los motores de aviación, como los de leasing o los de compraventa a plazos, se inscriben en la sección tercera del Registro Provincial de Bienes Muebles correspondiente al establecimiento mercantil al que estén afectos, puesto que son considerados bienes de equipo (M.-J. Morillas Jarillo, "La aeronave como cosa compuesta. La singularidad del régimen de los motores", en F. Martínez Sanz/ M.-V. Petit Lavall (dirs.), Estudios de Derecho aéreo: Aeronave y liberalización, Marcial Pons, Madrid, 2009, p. 100). Según las afirmaciones de la autora los datos que se anotan son el modelo, la marca, el número de serie del motor y el contrato relativo al motor (mediante testimonio, copia autorizada o modelo oficial). Con lo cual, esto provocaba que, a diferencia de lo que ocurriría si se realizase la inscripción en virtud del criterio anterior, no sólo sería competente el Registro Mercantil de Madrid, sino otros Registros Provinciales para llevar a cabo la inscripción de los motores. La diferencia entre inscribir los motores en la sección primera (buques y aeronaves) o en la sección tercera (maquinaria industrial, establecimientos mercantiles y bienes de equipo) del Registro de Bienes Muebles correspondiente según se ha explicado, puede que dependiese de si los motores estaban instalados en la aeronave -incribiéndose en la sección primera- o estaban almacenados -inscribiéndose en la sección tercera-. En cualquier caso, el principio de tracto sucesivo que caracteriza a los registros de bienes, llevaba a que el registro donde se 
29. Siguiendo con la idea anterior, ha sido finalmente la Resolución de 29 de febrero de 2016, de de la Dirección General de los Registros y del Notariado, por la que se aprueban los formularios de acceso al Registro Internacional sobre bienes aeronáuticos, la que ha establecido de forma clara que es el Registro de Bienes Muebles a cuyo cargo se encuentra el Registro de Aeronaves, el que será competente en materia de aeronaves de conformidad con el art. 177 del Reglamento del Registro Mercantil de 1956. En consecuencia, el Registro de Bienes Muebles Provincial de Madrid será el punto de acceso español, pues en la declaración efectuada en virtud del art, XIX.1 del Protocolo, se señala de forma genérica el Registro de Bienes Muebles ${ }^{114}$.

Por lo tanto, siguiendo con el contenido de la resolución, podrá solicitarse un código de autorización al punto de acceso español para las células de aeronaves y de helicópteros que hayan obtenido una matrícula definitiva o provisional en el Registro de Matrícula de Aeronaves Civiles.

En el caso de los motores, su inscripción a través del punto de acceso español es opcional. En cuyo caso si se trata de una aeronave completa lo que se pretende inscribir, será necesaria una solicitud diferente para cada bien registrable (célula y motor de aeronave) y el punto de acceso español emitirá un código diferente para cada uno de los bienes ${ }^{115}$.

30. El Registro de Bienes Muebles como punto de acceso autorizante. Esta designación nos puede llevar a afirmar, como se ha señalado antes al tratar el Registro Internacional, que España lo ha establecido así para que las garantías internacionales tengan que cumplir los mismos requisitos que los derechos nacionales inscritos en el Registro de Bienes Muebles.

En este sentido, el Real Decreto por el que se aprueba el Reglamento de matriculación de aeronaves civiles, señala que será el Registrador competente de Bienes Muebles el que deberá hacer constar la reserva de prioridad internacional en el Registro Internacional, una vez que se ha realizado la inscripción de la garantía o del derecho internacional en el Registro de Bienes Muebles, o desde el asiento de presentación cuando se prevea la reserva de prioridad sobre derechos de constitución futura ${ }^{116}$. Si bien la redacción de este párrafo es bastante confusa, porque señala en primer lugar que la garantía debe ser inscrita en el Registro de Bienes Muebles, así que podría interpretarse que para realizar dicha inscripción se deberán cumplir los requisitos señalados por nuestro ordenamiento para el acceso al mismo, incluido la calificación del título ${ }^{117}$. Además, parece que se hace un tratamiento diferenciado entre la garantía internacional y la garantía internacional futura, que el "Sistema de Ciudad del Cabo" no contempla, si entendemos que es a esto a lo que se refiere al hablar en dicho texto de derechos de constitución futura, pues señala que para los mismos será necesario que para su inscripción en el Registro Internacional, se tenga que realizar un asiento previo en el Registro de Bienes Muebles ${ }^{118}$. Por último, el precepto señala

hubiera inmatriculado el motor por primera vez sería competente para la inscripción de los demás actos y contratos sobre dicho motor. Por último, la Resolución de la DGRN establecía que no es posible hacer discriminación entre nacionales españoles y de otros Estados miembros de la Unión Europea. Así que, aunque el art. 179 del Reglamento del Registro Mercantil de 1956 establecía la obligatoriedad de la inscripción de las aeronaves de nacionalidad española, este precepto sólo puede entenderse teniendo en cuenta la normativa de la Unión Europea, y de los principios comunitarios de libre circulación de bienes y servicios y de libertad de establecimiento, que no permiten discriminación entre ciudadanos de los distintos Estados de la Unión Europea. Por lo tanto, las aeronaves, motores o piezas de repuesto pertenecientes a personas físicas o jurídicas de nacionalidad de cuaqluiera de los Estados miembros de la Unión Europea serían inscribibles en el Registro de Bienes Muebles competente, de acuerdo a las mismas normas que las aeronaves de españoles que se han señalado anteriormente (Resol. DGRN de 29 de enero de 2001, Anuario de la Dirección General de los Registros y del Notariado, vol. I, 2001, pp. 2183-2188). En este sentido, el art. 18 de la Ley de Navegación Aérea española de 1960 fue modificado para que los nacionales de los Estados de la Unión Europea pudiesen matricular sus aeronaves en el Registro de Matrícula de Aeronaves Civiles y obtener así la nacionalidad española, como si de un nacional español se tratara (art. 18 Ley 48/1960, de 21 de julio, sobre Navegación Aérea, BOE núm. 176, 23 julio 1960).

114 De la misma manera que se hace esta designación genérica en la disposición adicional sexta del RD 384/2015, de 22 de mayo, por el que se aprueba el Reglamento de matriculación de aeronaves civiles (BOE núm. 144, 17 junio 2015).

115 Resol. DGRN de 29 de febrero de 2016, por la que se aprueban los formularios de acceso al Registro Internacional sobre bienes aeronáuticos.

116 Disposición adicional sexta RD 384/2015, de 22 de mayo, por el que se aprueba el Reglamento de matriculación de aeronaves civiles, BOE núm. 144, 17 junio 2015.

117 I. Heredia Cervantes, “Análisis de la adhesión de España al Protocolo Aeronáutico del Convenio de Ciudad del Cabo", La Ley mercantil, núm. 21, 1 enero 2016, p. 8.

118 Ibidem, p. 9. 
que será el Registrador de Bienes Muebles competente el que haga constar la reserva de prioridad en el Registro Internacional, si bien al tratarse el Registro de Bienes Muebles de un punto de acceso autorizante, será la persona legitimada para realizar la inscripción en el Registro Internacional la que la realice, una vez obtenido el código de acceso solicitado al Registro de Bienes Muebles ${ }^{119}$. Por lo tanto, la letra a) de la disposición adicional sexta del Reglamento de matriculación de aeronaves ha generado bastantes interrogantes, a pesar de que dicha disposición se incluyó con el objetivo de que se implementase de manera eficaz y eficiente el "Sistema de Ciudad del Cabo" y por lo tanto, su Registro Internacional.

Tampoco las letras b) y c) de la disposición adicional sexta son muy claras ${ }^{120}$. Si bien en la letra b) podría deducirse que se está haciendo referencia a la posibilidad de que pueda realizarse la inscripción en el Registro Internacional a través del Registro de Bienes Muebles como punto de acceso autorizante, de los derechos o garantías no contractuales susceptibles de inscripción, cuya prioridad depende de su inscripción, contemplados en el art. 40 del Convenio ${ }^{121}$. Mientras que la letra c) podría interpretarse como los derechos o garantías no contractuales no inscritos, a los que hace referencia los arts. 39.1.a) y 39.1.b) del Convenio y que pueden ser inscritos en el Registro Internacional, una vez obtenido el código de acceso al Registro de Bienes Muebles. España como ya se ha señalado, ha hecho las pertinentes declaraciones conforme a los arts. 39.1.a) y 39.1.b) y 40 del Convenio señalando los derechos o garantías no contractuales que quiere que gocen de prioridad internacional, ya que cuando se adhirió sólo al Convenio en un primer momento, no las hizo ${ }^{122}$. Si bien al igual que en la letra a) de la disposición adicional segunda se vuelve a señalar que es necesaria la inscripción de tales derechos señalados en el Registro de Bienes Muebles, si bien el "Sistema de Ciudad del Cabo" no exige este requisito para su inscripción"

Pues bien, como ha sucedido en Estados Unidos, probablemente se le exijan a la garantía internacional más requisitos de los previstos en el corresponidente instumento internacional, a pesar de que se establece expresamente lo contrario en dicha disposición adicional sexta del Real Decreto.

Sin embargo, como se verá al analizar el nuevo Reglamento de matriculación de aeronaves civiles, en el caso de España se está intentando al menos, que el hecho de que se realice la inscripción de las garantías internacionales a través del Registro de Bienes Muebles, por ser el punto de acceso autorizante, no implique que se tengan que cumplir más requisitos para su inscripción que los establecidos en el "Sistema de Ciudad del Cabo" y en las Normas y Procedimientos del Registro Internacional.

\section{El Registro de Matrícula de Aeronaves Civiles}

31. Con la aprobación del nuevo Reglamento de matriculación de aeronaves en el 2015, que entró en vigor 1 de diciembre de 2015, se lleva a cabo una nueva regulación del Registro de Matrícula de Aeronaves que, desde su creación en 1969, y aunque había sido objeto de dos modificaciones importantes en 1972 y en 1996, no había sufrido en nuestra opinión un cambio tan profundo como el que se presenta en esta nueva norma ${ }^{124}$.

El Decreto 416/1969, de 13 de marzo, por el que se aprueba el Reglamento del Registro de Matrícula de Aeronaves surge como desarrollo reglamentario de la Ley española 48/1960, sobre Navegación Aérea, en cuyo artículo 28 se establece la creación de un Registro de Matrícula, en el que tendrán que ser matriculadas las aeronaves, en virtud del artículo 29 , y en cuyos artículos 28 a 33 se determina el régimen jurídico del Registro de Matrícula de Aeronaves ${ }^{125}$. Sin embargo, este Decreto es modificado, por primera vez, por el D 387/1972, de febrero, teniendo como objetivo primordial la coordinación entre

119 Idem, p. 9.

120 Disposición adicional sexta RD 384/2015, de 22 de mayo, por el que se aprueba el Reglamento de matriculación de aeronaves civiles, BOE núm. 144, 17 junio 2015.

121 I. Heredia Cervantes, "Análisis de la adhesión de España al Protocolo Aeronáutico del Convenio de Ciudad del Cabo", La Ley mercantil, núm. 21, 1 enero 2016, p. 9.

122 Ibidem, p. 10.

123 Idem, p. 10.

124 Parte expositiva RD 384/2015, de 22 de mayo, por el que se aprueba el Reglamento de matriculación de aeronaves civiles, BOE núm. 144, 17 junio 2015.

125 Preámbulo D 416/1969, de 13 de marzo, por el que se aprueba el Reglamento del Registro de Matrícula de Aeronaves, BOE núm. 71, 24 marzo 1969. 
el Registro de Matrícula y el Registro Mercanti1 ${ }^{126}$. Posteriormente, el Decreto 416/1969 fue modificado de nuevo por el Real Decreto 1709/1996, por dos razones fundamentales: una de estas razones era porque la pertenencia de España a la Unión Europea tenía como consecuencia que, la legislación hasta ese momento aplicable, creaba discriminación en la matriculación de aeronaves, por razones de la nacionalidad de sus poseedores y con esta modificación se daba pleno acceso al Registro a todas las aeronaves nacionales de cualquiera de los Estados miembros; la otra, porque la evolución de la aviación civil había provocado que no sólo fuera el dominio la forma de adquisición de las aeronaves, sino que las grandes compañías aéreas optaban por otras fórmulas como el arrendamiento, con o sin opción de compra, la venta a plazos u otros contratos que llevaban aparejados la adquisición de la posesión ${ }^{127}$.

En esta nueva normativa sobre el Registro de Matrícula de Aeronaves, además de señalar la naturaleza administrativa del mismo, se establecen las funciones de dicho Registro, cuyo ámbito se extiende a todo el territorio nacional, y que son: asignación de las marcas de nacionalidad y matrícula de las aeronaves; e inscripción de las mismas, haciendo constar de forma auténtica las titularidades y demás vicisitudes jurídicas que les afecten, tales como propiedades, arrendamientos, embargos, hipotecas, novaciones de contratos o cancelaciones, y las características técnicas de las aeronaves objeto de inscripción ${ }^{128}$. Sin embargo, la calificación de los títulos jurídicos aportados para la inscripción es realizada por el Registro de Bienes Muebles.

32. El nuevo Reglamento reestructura el Registro de Matrícula, haciendo más sencillos sus trámites y subsanando sus deficiencias, a la vez que ha aportado mayor agilidad, de manera que se ha configurado claramente como un registro administrativo diferenciado y de distinta naturaleza que el Registro de Bienes Muebles. Aunque en nuestra opinión esto ya estaba bastante claro en el antiguo Reglamento de Registro de Matrícula de Aeronaves con respecto al Registro Mercanti ${ }^{129}$. Los pilares en los que se basa dicho Reglamento son: establecer un régimen registral único para todas las aeronaves y suprimir los especiales, quedando eliminados la normativa específica relativa a la matriculación de aeronaves de estructura ligera y de aeronaves privadas de uso no mercantil; establecer las aeronaves que están exentas de inscripción en el Registro de Matrícula de Aeronaves; incorporar y ordenar la regulación fragmentaria que existe sobre las matrículas de prueba, a la vez que regular un concepto novedoso, la reserva de matrícula de la aeronave; articular la relación entre el Registro de Matrícula y el Registro de Bienes Muebles; y establecer las previsiones necesarias para permitir la aplicación del Convenio de Ciudad del Cabo relativo a garantías internacionales sobre elementos de equipo móvil y su Protocolo sobre elementos de equipo aeronáutico ${ }^{130}$.

33. El Real Decreto establece que accederán al Registro de Matrícula de Aeronaves Civiles las aeronaves de nacionales de cualquiera de los Estados miembros del Espacio Económico Europeo; y las de nacionales de terceros Estados, siempre que cuenten con residencia habitual en España, si se trata de

126 Esta modificación se produjo en ejecución de la disposición adicional de la Ley 113/1969, de 30 de diciembre, de modificación de los artículos 33 y 130 de la Ley 48/1960, de 21 de julio, sobre Navegación Aérea (BOE núm. 313, 31 diciembre 1969), en virtud de la cual se encomendó al Gobierno coordinar el Reglamento de Registro de Matrícula de aeronaves con lo establecido en esta Ley 113/1969 (D 387/1972, 10 febrero, por el que se modifican los artículos $7^{\circ}, 8^{\circ}, 16,18,19,24,25,27$, 36, 37 y 38, disposiciones adicionales y disposiciones transitorias del Reglamento del Registro de Matrícula de Aeronaves, aprobado por el D 416/1969, de 13 de marzo, BOE núm. 50, 28 febrero 1972). De hecho para justificar su desarrollo en el preámbulo de dicha Ley 113/1969 se dice textualmente: "No es misión de dicho Registro de Matrícula la constitución y señalamiento de efectos en cuanto a tercero de los actos o contratos de carácter jurídico privado, sino la de reflejar su existencia, una vez constituidos válidamente en su esfera propia, y por ello es aconsejable modificar aquellos artículos de la Ley que ponen de manifiesto aparentes contradicciones en nuestra legislación a la vez que se ordena la concordancia que debe existir entre el Registro Mercantil y el de Matrícula". Esto es como consecuencia de que en la Ley 48/1960 no sólo se señala la naturaleza administrativa del Registro de Matrícula de Aeronaves en su art. 28, sino que en su art. 29 se añade que en él se harán constar los actos, contratos y vicisitudes en general que afecten a la aeronave.

127 Preámbulo RD 1709/1996, de 12 de julio, por el que se modifica el Registro de Matrícula de Aeronaves aprobado por el D 416/1969, de 13 de marzo, BOE núm. 187, 3 agosto 1996.

128 Dictamen emitido por el Consejo de Estado en el expediente núm. 128/2015, de 17 de marzo de 2015, p. 10.

129 Dictamen emitido por el Consejo de Estado en el expediente núm. 128/2015, de 17 de marzo de 2015, p. 11.

130 Parte expositiva RD 384/2015, de 22 de mayo, por el que se aprueba el Reglamento de matriculación de aeronaves civiles, BOE núm. 144, 17 junio 2015. 
una persona física, o con establecimiento permanente en España, en el caso de que fuese una persona jurídica, y además dichas aeronaves sean destinadas a uso privado ${ }^{131}$.

Los contratos en virtud de los cuales las personas físicas o jurídicas pueden estar en posesión de la aeronave para proceder a su matrículación son: contratos de propiedad, de alquiler o cualquier otro que la Ley española contemple ${ }^{132}$.

34. En el capítulo II del Reglamento de matriculación de aeronaves civile se trata uno de los aspectos fundamentales de esta normativa, que es la distinción entre los dos tipos de asientos que regula y que son: inscripciones y anotaciones ${ }^{133}$. Las inscripciones, que serán de matriculación y de cancelación, sólo surtirán efectos administrativos para la operación de las aeronaves y las consecuencias asociadas a ella, sin perjuicio de las consecuencias tributarias que puedan derivarse de la matriculación de las aeronaves. En cuanto a las anotaciones, se producen a los efectos exclusivos de publicidad, de manera que se realizarán las anotaciones relativas a cambios de titularidad, es decir, cualquier acto o contrato por el que se adquiera o transmita la propiedad, contratos de arrendamiento o cualquier otro título traslativo de la posesión o uso de la aeronave, junto con las novaciones de dichos contratos posesorios si implican cambio de la posición jurídica del poseedor o modificación subjetiva de una de las partes del contrato; además, se anotarán las cargas, gravámenes e hipotecas que afecten a las aeronaves; así como también serán objeto de anotación las vicisitudes técnicas, que supongan cambio en el modelo de las aeronaves ${ }^{134}$. Sin embargo, están excluidos los contratos de arrendamiento de corta duración, es decir, los contratos de arrendamiento o subarrendamiento igual o inferior a seis meses ${ }^{135}$.

La distinción entre estos dos tipos de inscripciones es una de las novedades más importantes introducidas por esta norma con respecto a su antecesor, con el objetivo de diferenciar los aspectos registrados sobre las aeronaves para la atribución de la nacionalidad de la aeronave, es decir con fines administrativos, de los aspectos registrados sobre las aeronaves relacionados con la propiedad o la posesión de la aeronave, así como las cargas y gravámenes que recaigan sobre las mismas.

En cuanto a los libros actuales que se venían llevando en el Registro de Matrícula de Aeronaves, tales como el libro de presentación de documentos, el libro de matrícula, el libro de tasas y el libro de estadística, con la entrada en vigor del nuevo Reglamento quedarán derogados, pues las inscripciones y anotaciones se van a llevar a cabo de la siguiente forma: "se abrirá una hoja de asiento para cada aeronave en la que se hará constar su matriculación, los datos técnicos de la aeronave y sus vicisitudes técnicas, la referencia al título jurídico, los seguros aéreos obligatorios a los que está sujeta, las cargas y gravámenes, así como los cambios de titularidad que se produzcan en relación con ella. La hoja de asiento para cada aeronave se cerrará con la cancelación de la matrícula“"136.

131 Art. 2 RD 384/2015, de 22 de mayo, por el que se aprueba el Reglamento de matriculación de aeronaves civiles, BOE núm. 144, 17 junio 2015. Dicho precepto remite al art. 18 de la Ley 48/1960, de 21 de julio, sobre Navegación Aérea (BOE núm. 313, 31 diciembre 1969), para establecer qué aeronaves son inscribibles en el Registro de Matrícula de Aeronaves Civiles.

132 Art. 11 RD 384/2015, de 22 de mayo, por el que se aprueba el Reglamento de matriculación de aeronaves civiles, BOE núm. 144, 17 junio 2015.

133 Art. 8.1 RD 384/2015, de 22 de mayo, por el que se aprueba el Reglamento de matriculación de aeronaves civiles, BOE núm. 144, 17 junio 2015.

134 Art. 8.2 RD 384/2015, de 22 de mayo, por el que se aprueba el Reglamento de matriculación de aeronaves civiles, BOE núm. 144, 17 junio 2015. Los cambios de modelo de la aeronave serán comunicadas al Registro de Matrícula de Aeronaves Civiles por la Agencia Estatal de Seguridad Aérea (art. 30 RD 384/2015, de 22 de mayo, por el que se aprueba el Reglamento de matriculación de aeronaves civiles, BOE núm. 144, 17 junio 2015).

135 Art. 8.3 RD 384/2015, de 22 de mayo, por el que se aprueba el Reglamento de matriculación de aeronaves civiles, BOE núm. 144, 17 junio 2015. Estos contratos de arrendamiento se recogen en el art. 27 del Reglamento (RD 384/2015, de 22 de mayo, por el que se aprueba el Reglamento de matriculación de aeronaves civiles, BOE núm. 144, 17 junio 2015).

136 Art. 8.4 RD 384/2015, de 22 de mayo, por el que se aprueba el Reglamento de matriculación de aeronaves civiles, BOE núm. 144, 17 junio 2015. También, existía un libro de motores que se introdujo en la primera modificación que se hizo del Reglamento de Registro de Matrícula de Aeronaves de 1972, pero que fue eliminado finalmente en la segunda modificación realizada de dicho Reglamento en 1996, sin ninguna justificación (arts. 2.3 y 3 RD 1709/1996, de 12 de julio, por el que se modifica el Registro de Matrícula de Aeronaves aprobado por el D 416/1969, de 13 de marzo, BOE núm. 187, 3 agosto 1996; art. 8.2 D 416/1969, de 13 de marzo, por el que se aprueba el Reglamento del Registro de Matrícula de Aeronaves (BOE núm. 71, 24 marzo 1969), con la redacción realizada por el D 387/1972, 10 febrero, por el que se modifican los artículos $7^{\circ}, 8^{\circ}, 16$, 
35. En el artículo 10 del Real Decreto, también se aborda otro aspecto fundamental, que es la relación del Registro de Matrícula de Aeronaves Civiles con el Registro de Bienes Muebles. En una redacción inicial de este artículo se establecía la obligatoriedad de la inscripción de todas las aeronaves en ambos registros. Sin embargo, en la versión definitiva se ha modificado este aspecto porque en el Registro de Bienes Muebles, aunque son inscribibles las aeronaves tanto en virtud de título de transmisión de su propiedad como de título traslativo de la posesión -al igual que en el Registro de Matrícula de Aeronaves Civiles-, según la normativa existente, la primera inscripción de la aeronave en el Registro de Bienes Muebles debe ser la del dominio ${ }^{137}$. En este sentido, aunque inicialmente las aeronaves destinadas a fines industriales o mercantiles eran objeto de inscripción en el Registro Mercantil, la Dirección General de los Registros y del Notariado (DGRN) en una resolución del año 2000, aclaró que todas las aeronaves podían ser objeto de inscripción al señalar: "En la sección de buques y aeronaves (sección primera) del nuevo Registro de Bienes Muebles se deben practicar todas las inscripciones de actos y contratos relativas a embarcaciones y aeronaves, con independencia (con relación a los buques) de la lista en la que estén inscritas en el Registro administrativo correspondiente. Cada uno de los actos, contratos y gravámenes (compraventas, al contado o a plazos, arrendamientos, hipoteca naval o mobiliaria, anotación de embargo o de demanda, ejecución forzosa, etcétera) que se realicen sobre tales bienes serán calificados y en su caso inscritos o anotados preventivamente dentro de dicha Sección por el Registrador de Bienes Muebles"138.

Sin embargo, si se trata de arrendmientos de aeronaves extranjeras, el título de arrendamiento no podría inscribirse en el Registro de Bienes Muebles, puesto que como ya se ha mencionado, en virtud del art. 180 del Reglamento del Registro Mercantil de 1956, no son inscribibles los arrendamientos de aeronaves cuando no existe una inscripción previa de dominio sobre la misma ${ }^{139}$. Aunque se debe aclarar, que hay opiniones que señalan que dicho art. 180 del Reglamento del Registro Mercantil de 1956 quedaría derogado tras este RD 384/2015, de manera que sí se podrían inscribir los arrendamientos en el Registro de Bienes Muebles, aunque sea la primera inscripción. Según los expertos consultados, el precepto quedaría derogado porque ambas son normas del mismo rango, pero lo cierto es que no existe ninguna resolución de la Dirección General de los Registros y del Notariado que pueda sustentar esta aseveración. De hecho, en la práctica se está realizando la inscripción de contratos de arrendamiento sobre aeronaves en el Registro de Bienes Muebles cuando se trata de la primera inscripción relativa a dichas aeronaves, en contra de lo señalado por el art. 180 del Reglamento del Registro Mercantil de 1956.

Por lo tanto, la primera inscripción de una aeronave se realizará en el Registro de Matrícula, el cual analizada la documentación presentada, asignará a la aeronave una matrícula con el carácter de provisional y emitirá un certificado de matrícula provisional. Cuando se trate de una aeronave inscribible en el Registro de Bienes Muebles, una vez practicada la inscripción del título jurídico en dicho Registro, se realizará la inscripción definitiva de la aeronave, emitiéndose, por tanto, el certificado de matrícula definitivo. En caso de que no sea posible la inscripción de la aeronave en el Registro de Bienes Muebles, se procederá a la inscripción definitiva del título jurídico aportado en el Registro de Matrícula de Aeronaves Civiles y a la emisión del certificado de matrícula definitivo, en un plazo máximo de tres meses ${ }^{140}$. Los actos jurídicos posteriores a la matriculación de la aeronave que sean inscribibles en el Registro

18, 19, 24, 25, 27, 36, 37 y 38, disposiciones adicionales y disposiciones transitorias del Reglamento del Registro de Matrícula de Aeronaves, aprobado por el D 416/1969, de 13 de marzo (BOE núm. 50, 28 febrero 1972)).

137 Art. 180 Reglamento del Registro Mercantil de 1956, aprobado por el Decreto de 14 de diciembre de 1956, BOE núm. 66, 7 marzo 1957; corrección de errores en BOE núm. 73, 14 marzo 1957. Aunque el Reglamento del Registro Mercantil vigente es el de 1996, en lo que respecta a la inscripción de buques y aeronaves sigue estando en vigor el Reglamento del Registro Mercantil de 1956, arts. 145 a 190. Vid. Disp. Trans. 13a. del RD 1784/1996, de 19 de julio, por el que se aprueba el Reglamento del Registro Mercantil, BOE núm. 184, 31 julio 1996.

138 Resol. DGRN de 11 de abril de 2000, sobre determinadas cuestiones derivadas de la creación del Registro de Bienes Muebles. Vid. art. 179 Reglamento del Registro Mercantil de 1956, aprobado por el Decreto de 14 de diciembre de 1956, BOE núm. 66, 7 marzo 1957; corrección de errores en BOE núm. 73, 14 marzo 1957.

139 J.-D. Parada VÁzquez, Derecho Aeronáutico, Industria Gráfica MAE, S.L., Madrid, 2000, pp. 276, 277 y 280.

140 Art. 15.2 RD 384/2015, de 22 de mayo, por el que se aprueba el Reglamento de matriculación de aeronaves civiles, BOE núm. 144, 17 junio 2015. 
de Bienes Muebles, conforme a su legislación específica, se inscribirán primero en dicho Registro. Es importante destacar que la comunicación entre ambos Registros se realizará por vía telemática.

36. Por último, señalar que como ya se ha señalado al estudiar el Registro de Bienes Muebles, en el Reglamento de matriculación de aeronaves civiles se ha añadido la disposición adicional sexta para permitir la aplicación del Convenio y su Protocolo Aeronáutico. Sin embargo, la redacción del precepto no es muy clara, ni coherente con el funcionamiento del Registro Internacional.

A pesar de lo señalado, en realidad no se ha venido realizando ninguna inscripción en el Registro de Bienes Muebles relativas a garantías internacionales. Cuando en el Registro de Bienes Muebles se solicitaban los códigos alfanuméricos, para realizar posteriormente la inscripción en el Registro Internacional de la correspondiente garantía internacional, se debe señalar que no se anotaba carga alguna en base al formulario presentado, puesto que la aportación de dicho formulario se asentaba en el libro de entrada como lo haría cualquier otro documento aportado al registro, contuviera o no materia sujeta a inscripción. Así que no se pasaba al diario de operaciones y tampoco a los libros de inscripciones.

Se ha considerado que esta situación era muy peligrosa para la seguridad del tráfico, ya que si se solicitaba una certificación de cargas en relación a una aeronave y en los libros registrales no aparecía ninguna, el registrador tendría que certificar la libertad de cargas de dicha aeronave, aún cuando hubiera autorizado un código de acceso al Registro Internacional.

Por esta razón, ante la consulta planteada por el registrador encargado del Registro de Aeronaves, la DGRN resolvió mediante informe de fecha 29 de abril de 2016, que sería posible una anotación preventiva en base al formulario presentado, al no ser el mismo susceptible de inscripción debido a su reducido contenido ${ }^{141}$. Si se ejerciese la potencial garantía internacional, dicha anotación preventiva evitaría la aparición del tercero en virtud del art. 34 de la Ley Hipotecaria, dado que el adquirente de algún derecho sobre la aeronave no podría alegar desconocimiento de la garantía internacional ${ }^{142}$.

Efectivamente en el informe de la consulta realizada el 28 de abril de 2016, se establece la posibilidad de que el término "inscripción", de la disposición adicional sexta del Reglamento de matriculación de aeronaves civiles, sea interpretado en términos amplios como asiento registral y no necesariamente como inscripción ${ }^{143}$. De manera que al no reunir los requisitos necesarios para su inscripción conforme a la Ley española, sería posible realizar una anotación preventiva, como se ha señalado antes ${ }^{144}$. Dicha "anotación preventiva de garantía internacional" se convertiría en definitiva con efecto retroactivo en caso de que finalmente se adquiera el derecho anotado conforme a la Ley española, pero en cualquier caso la garantía internacional subisistirá con los efectos propios del Convenio y su Protocolo Aeronáutico. Se propone también que el tiempo establecido para la práctica de una anotación preventiva sea de 4 años como plazo general, afirmación que tiene su fundamento legal en la disposición adicional segunda de la Ley 28/1998, de 13 de julio de Venta a Plazos de Bienes Muebles y que sería aplicable por analogía ${ }^{145}$.

De manera, que parece ser que se están respetando las disposiciones del Convenio, así como la disposición adicional sexta, que señalan que las legislaciones nacionales no pueden establecer más formalidades que las recogidas en "Sistema de Ciudad del Cabo" y las Normas y Procedimientos del Registro Internacional, y este extremo no ha sido modificado por la adhesión española.

\section{La práctica registral en la materia}

37. A continuación se muestra cómo viene realizándose en la práctica, las inscripciones de las garantías en el Registro Internacional, cuando se ha designado al Registro de Bienes Muebles como

\footnotetext{
141 Vid. Informe consulta realizada por el Registador Mercantil y de Bienes Muebles de Madrid, de 28 de abril de 2016.

142 Art. 34 Decreto de 8 de febrero de 1946 por el que se aprueba la nueva redacción oficial de la Ley Hipotecaria, BOE núm. 58, 2 febrero 1946.

143 Vid. Informe consulta realizada por el Registador Mercantil y de Bienes Muebles de Madrid, de 28 de abril de 2016.

144 Vid. Informe consulta realizada por el Registador Mercantil y de Bienes Muebles de Madrid, de 28 de abril de 2016.

145 Disposición adicional segunda de la Ley 28/1998, de 13 de julio Venta a Plazos de Bienes Muebles, BOE núm. 167, 14 Julio 1998.
} 
punto de acceso autorizante. De la misma forma que se explica cómo se está implantando en España, la "autorización irrevocable para solicitar la cancelación de la matrícula y el permiso de exportación", que corresponde a las siglas en inglés IDERA, y que será explicado después.

\section{Inscripción de las garantías en el Registro de Bienes Muebles}

38. El resultado en la práctica de la adhesión de España al Convenio de Ciudad del Cabo y su Protocolo, se ha materializado en la presentación en el Registro de Aeronaves (sección perteneciente al Registro Provincial de Bienes Muebles de Madrid), de unos sencillos formularios introducidos por la resolución de la DGRN de 29 de febrero de 2016, en base a los cuales el mencionado registro nacional concede un código alfanumérico a los interesados para que, mediante dicho código, puedan acceder a la inscripción de su derecho en el Registro Internacional.

El tiempo que se tarda en conceder el código es de 24 horas. A partir de la concesión del código de referencia por el registro español, es al interesado al que le corresponde directamente la tramitación, por lo que dicho registro no es responsable de las demoras que a partir de ese momento se produzcan. Esto es importante señalarlo, porque la garantía internacional goza de prioridad en las condiciones que señala el Convenio desde el momento de su inscripción en el Registro Internacional, y si esta no se produce finalmente, dicha garantía internacional no gozará de prioridad solamente porque el interesado haya conseguido el código alfanumérico ${ }^{146}$.

39. En definitiva, no se pueden pedir más requisitos que los del formulario que se debe completar a través de la web del Registro Mercantil de Madrid y que son los siguientes: datos del solicitante, descripción del bien (matrícula, modelo, marca, carga y pasaje, motores y $\mathrm{n}^{\mathrm{o}}$ de serie), negocio jurídico, intervinientes y firma ${ }^{147}$.

\section{Inscripción de una IDERA (Irrevocable Deregistration and Express Request Authorization)}

40. En el instrumento de adhesión al Protocolo, además de las declaraciones ya mencionadas, España hizo la declaración de conformidad con el art. XXX.1 del Protocolo, para aplicar el art. XIII del Protocolo. En virtud de este precepto, el acreedor y el deudor pueden pactar a favor de aquel una autorización irrevocable para solicitar la cancelación de la matrícula y el permiso de exportación de la aeronave, en caso de incumplimiento del deudor. Esta autorización se tendrá que realizar de acuerdo con el formulario anexo al Protocolo y dicha autorización deberá tener insribirse en el Registro de Matrícula de Aeronaves Civiles ${ }^{148}$.

Además, en el caso de que el acreedor desee hacer efectiva dicha autoriación, deberá avisar de la exportación de la aeronave con un tiempo razonable y por escrito a las partes interesadas ${ }^{149}$. Una vez realizada la notificación las autoridades del Estado de Matrícula, deberán dar efecto al IDERA, y siempre que el acreedor les certifique, si dicha autoridad lo requiere, que todas las garantías inscritas que tienen

146 A fecha 8 de junio de 2016, el Registro de Aeronaves había concedido 103 autorizaciones de acceso, que no son pocas si se tiene en cuenta que el "Sistema de Ciudad del Cabo" entró en vigor para España el 1 de marzo del 2016.

147 Formulario disponible en línea en https://www.rmercantilmadrid.com/rmm/Downloads/Impresos/BienesMuebles3.pdf (consultado el 16 de noviembre de 2016).

148 Art. XIII.2 del Protocolo sobre cuestiones específicas de los elementos de equipo aeronáutico, del Convenio relativo a garantías internacionales sobre elementos de equipo móvil. Decisión del Consejo núm. 2009/370/CE, de 6 de abril de 2009 , relativa a la adhesión de la Comunidad Europea al Convenio relativo a garantías internacionales sobre elementos de equipo móvil y su Protocolo sobre cuestiones específicas de elementos de equipo aeronáutico, adoptados conjuntamente en Ciudad del Cabo el 16 de noviembre del 2001, DO núm. L 121, 15 mayo 2009.

149 Art. IX.6 del Protocolo sobre cuestiones específicas de los elementos de equipo aeronáutico, del Convenio relativo a garantías internacionales sobre elementos de equipo móvil. Decisión del Consejo núm. 2009/370/CE, de 6 de abril de 2009, relativa a la adhesión de la Comunidad Europea al Convenio relativo a garantías internacionales sobre elementos de equipo móvil y su Protocolo sobre cuestiones específicas de elementos de equipo aeronáutico, adoptados conjuntamente en Ciudad del Cabo el 16 de noviembre del 2001, DO núm. L 121, 15 mayo 2009. 
prioridad respecto a la del acreedor han sido canceladas o que los titulares de esas garantías han dado su consentimiento para la cancelación de la matrícula y la exportación ${ }^{150}$.

España ha tenido que hacer una declaración conforme al art. XXX.1, para que en el caso del IDERA no sea de aplicación la previsión recogida en el art. 54.2 del Convenio, conforme a la cual es necesaria la intervención de un tribunal.

41. Por último, se va a abordar el problema que se plantea en España derivado de la constancia registral del IDERA. En primer lugar para que el pacto comisorio que supone el IDERA, que no tiene cabida en el Derecho español, pueda tener reflejo en el Registro de Bienes Muebles y en el Registro de Matrícula es necesario que el contrato en el que se inserta el IDERA, o al que se incorpora posteriormente, haya accedido al plano internacional, es decir que haya sido inscrito en el Registro Internacional, tras haber realizado el procedimiento señalado anteriomente.

En segundo lugar, el El IDERA, no es otra cosa que un pacto que forma parte de un contrato, y que por tanto, puede venir integrado en el contrato como una cláusula más o bien, agregarse por vía de novación objetiva del contrato principal. En cualquier caso, para su constancia en el Registro de Bienes Muebles sería necesario que cumpliese los requisitos exigidos por la legislación española, de tal manera que las firmas fuesen legitimadas.

En consecuencia, el procedimiento para la constancia registral del IDERA podría ser el siguiente:

a) Contrato inscrito con anterioridad al Convenio. No podría presentarse un IDERA salvo que se haya presentado el formulario dándole a aquel el carácter de aviso de garantía. En este caso el IDERA deberá presentar las firmas que lo autorizan.

b) Contrato no inscrito adjuntando formulario. En este caso el IDERA podría formar parte del clausulado, con lo que tendría las firmas legitimadas al estarlo las del contrato, o bien acompañarse en documento adjunto, en cuyo caso deberá tener sus firmas independientemente legitimadas.

c) Contrato no inscrito y sin adjuntar formulario. No cabría introducir un IDERA, el cual, de pactarse en el contrato a inscribir, sería objeto de denegación en nuestro derecho y no encontrarnos bajo la aplicación del Convenio.

d) Presentación de formulario sin documentación. Si se presenta el formulario acompañado del IDERA, el Registro de Bienes Muebles se limitará a dar el código alfanumérico de acceso al Registro Internacional y a la práctica de una "anotación preventiva de garantía internacional”. Pero el IDERA no tendrá en este caso reflejo registral.

\section{Cuestiones pendientes}

42. Como consecuencia del ámbito tan amplio que, en relación con las garantías internacionales y otros derechos o garantías, cubre el "Sistema de Ciudad Cabo", es bastante previsible que existan aspectos que no hayan sido resueltos por el Convenio de Ciudad del Cabo y su Protocolo Aeronáutico. Por lo que se van a explicar los asuntos pendientes relacionados con la "implementación" en España del Registro Internacional, algunos de los cuales ya se han apuntado a lo largo del presente trabajo.

43. En cuanto al ámbito de aplicación personal del Convenio y su Protocolo Aeronáutico, si el deudor está situado en un Estado contratante, la garantía internacional constituida puede acceder vía telemática al Registro Internacional, con independencia de que el Estado de registro sea o no un Estado contratante. Pero si el Estado contratante de registro de la célula de aeronave o del helicóptero, establece

150 Art. IX.5 del Protocolo sobre cuestiones específicas de los elementos de equipo aeronáutico, del Convenio relativo a garantías internacionales sobre elementos de equipo móvil. Decisión del Consejo núm. 2009/370/CE, de 6 de abril de 2009, relativa a la adhesión de la Comunidad Europea al Convenio relativo a garantías internacionales sobre elementos de equipo móvil y su Protocolo sobre cuestiones específicas de elementos de equipo aeronáutico, adoptados conjuntamente en Ciudad del Cabo el 16 de noviembre del 2001, DO núm. L 121, 15 mayo 2009. 
un punto de acceso nacional, deben respetarse los requisitos para su incripción en el Registro Internacional a través de dicho punto de acceso nacional.

Por otro lado, si el deudor no está situado en un Estado contratante y no se puede crear la correspondiente garantía internacional, pero el Estado de registro es un Estado contratante con punto de acceso nacional, se acudiría a él para el acceso al Registro internacional del resto de garantías o derechos distintos de la garantía internacional previstos en el Convenio y su Protocolo Aeronáutico.

44. No obstante, la transmisión a través de los puntos de acceso nacionales de las células de aeronaves y de los helicópteros, no es obligatorio para la inscripción con respecto a los motores de aeronaves -ya que en todos los Estados no se les asigna un número de registro o matrícula, como ocurre con las células o los helicópteros-, aunque se puede realizar a través de ellos. En consecuencia, si no se realiza la inscripción de manera correcta, un motor podría llegar a incribirse dos veces utilizando distintas formas de acceso al Registro Internacional. Este problema no sucede con las células de aeronaves y los helicópteros, los cuales disponen de matrícula para su identificación.

En la misma línea de lo anteriomente señalado, el hecho de que el Registro Internacional haya dado la posibilidad de que cada Estado contratante designe uno o varios puntos de acceso nacionales, y de establecer si se trata de un punto de acceso directo o autorizante, abre la posibilidad a que un mismo objeto aeronáutico sea inscrito varias veces, a través de puntos de acceso de distintos Estados, sobre todo en el caso de los motores. Así pues, si un Estado contratante designa un punto de acceso autorizante para inscribir una garantía sobre una célula de aeronave o un helicóptero matriculados en dicho Estado contratante, pero la inscripción no respeta el procedimiento establecido, tal registro no será válido y el Registrador advertirá de ello al usuario mediante un mensaje electrónico. De la misma manera que si un Estado contratante ha establecido que la inscripción de las garantías sobre las células de las aeronaves o los helicópteros se realice obligatoriamente a través de un punto de acceso directo, pero no se efectúa a través del mismo, el Registrador procederá de la misma forma. Sin embargo, en el caso de los motores como no es obligatoria la inscripción de su garantía o derecho a través del punto de acceso nacional designado, se puede optar o bien por realizar dicha inscripción a través del punto de acceso nacional, ya sea autorizante o directo, o bien directamente a través del Registro Internacional.

45. No se debe olvidar además, que no se puede designar un punto de acceso nacional, para la inscripción de avisos de garantías nacionales o de garantías o derechos no contractuales inscribibles constituidos bajo las Leyes de otro Estado. Por lo tanto, un Estado contratante sólo puede realizar a través de su punto de acceso nacional, la inscripción de los avisos de garantías nacionales o derechos o garantías contemplados en el art. 40 del Convenio cuando se han constituido bajo su Derecho nacional.

46. En relación con la primera inscripción de las aeronaves en el Registro de Bienes Muebles en virtud de contratos de arrendamientos, se debe señalar que es necesario que se redacte una resolución de la Dirección General de los Registros y del Notariado en el que se refleje esta posibilidad.

Aunque en la práctica se vienen realizando las primeras inscripciones sobre aeronaves en el Registro de Bienes Muebles en base a contratos de arrendamiento, esto es contrario a lo dispuesto en el art. 180 del Reglamento del Registro Mercantil de 1956. A pesar de que existen opiniones en favor de que dicho precepto quedaría derogado por el Reglamento de matriculación de aeronaves, pues se trataría de normas del mismo rango.

47. Por último, se debería ofrecer la posibilidad de ejecución del IDERA desde el momento en que la documentación se presenta en el Registro de Matrícula para la obtención de la matrícula provisional. Esto es especialmente relevante, porque si el operador incumple sus obligaciones contractuales desde el primer momento, el acreedor se queda desprotegido al no poder utilizar el IDERA para recuperar el objeto aeronáutico, por su falta de inscripción previa. 